\title{
Sensitivity analysis of the dynamic response of an electronic fuel injector regarding fuel properties and operating conditions
}

\author{
Nao $\mathrm{Hu}^{1,2, *}$, Jianguo Yang ${ }^{1,3}$, Peilin Zhou ${ }^{2}$ \\ 1. School of Energy and Power Engineering, Wuhan University of Technology, 430063, Wuhan, PRC; \\ 2. Department of Naval Architecture, Ocean and Marine Engineering, University of Strathclyde, G4 0LZ, Glasgow, UK; \\ 3. Key Laboratory of Marine Power Engineering \&Technology, Ministry of Communications, 430063, Wuhan, PRC; \\ $1 \quad *$. Corresponding author.
}

2 Abstract: The effects of fuel properties, such as its bulk modulus, density and viscosity, on the

3 injector dynamic response (needle valve opening/closing delay and needle valve 4 opening/closing time) were investigated individually. Firstly, an electronic fuel injector model 5 was built and validated by injection rate and injection mass at three different rail pressures and 6 three different activation times. Secondly, a DOE (design of experiment) model was built and 7 the Uniform Latin Hypercube (ULH) design method was applied to study the influences of the 8 fuel properties on the injector dynamic response from a statistical point of view. The effects of

9 the fuel properties were compared by using a SS-ANOVA (smoothing spline analysis of 10 variance) method at both a low and a high rail pressure. The bulk modulus was found to play 11 a dominant role in influencing the valve opening/closing delay at the low rail pressure. 12 However, at the high rail pressure, the effects of the viscosity are prominent, while the effects

*Email: nao.hu.0128@gmail.com (N. Hu) 
13 of the bulk modulus and the density are negligible. Additionally, how these fuel properties

14 affect the dynamic response were reported by RSM (Response Surface Method) function charts,

15 and the details of the pressure differences and needle valve movements were also disclosed.

16 Key words: electronic fuel injector; fuel properties; dynamic response; DOE

\begin{tabular}{|llll|}
\hline Nomenclature & & & \\
1D & one dimensional & $\mathrm{ULH}$ & Uniform Latin Hypercube \\
AC & accumulation chamber & $v$ & $\begin{array}{l}\text { pressure wave propagation } \\
\text { speed }\end{array}$ \\
Ab_Visc & absolute viscosity & & \\
B & bulk modulus & Greek symbols & \\
Bulk_M & bulk modulus & $\mu$ & absolute viscosity \\
CC & control chamber & $\rho$ & density \\
$C_{f}$ & friction coefficient & $\tau$ & delay \\
$D$ & pipe diameter & & \\
Dens & density & Units & \\
DOE & design of experiments & $\mathrm{cP}$ & centipoise \\
HPCR & high pressure common rail & $\mathrm{K}$ & Kelvin \\
$L$ & pipe length & $\mathrm{kg} / \mathrm{mm}{ }^{3}$ & kilograms per cubic \\
millimetre
\end{tabular}




\section{Introduction}

19 Electronic fuel injectors play an indispensable role in HPCR fuel injection systems and interest numerous researchers to improve their performance. A lot of work has been undertaken in the nozzle area, such as the nozzle structure types [1-3], the hole numbers and arrangements [4-7] and the internal cavitation [8-11] of orifices. They have been thoroughly studied because they have a direct effect on the fuel injection and atomisation. The spray characteristics [12-14], the penetration [15-17] and the lift-off length $[18,19]$ have also been investigated by experiment or simulation in many studies. With the continual focus on the emissions of diesel engines, the use of different alternative fuels has come into the sight of researchers [20]. The differences in fuels lie in their properties [21], such as the density, viscosity and bulk modulus. Fuel properties significantly affect the spray characteristics of a fuel injector, as were studied by Dernotte et al. [22] and Payri et al. [23]. In addition, fuel properties change in vast ranges of different pressures and temperatures, as were revealed by Salvador et al. [24] and Desantes et al. [25].

The multi-injection performance of a solenoid injector was evaluated by Salvador et al. [26] by using a standard diesel fuel and a biodiesel fuel. The biodiesel fuel was identified as have a larger valve opening delay and valve opening time due to it have a larger viscosity. This implies that the fuel properties may have an effect on the dynamic response of a fuel injector. However, to date, only a few studies have found considered the effects of fuel properties on the dynamic response of electronic fuel injectors. Han et al. [27] experimentally investigated the injection process of three fatty acid esters on an HPCR system. He pointed out that fatty acid esters have larger injection delays and smoother rising slopes of the injection rate than diesel fuel. They also indicated that a reduced injection delay, along with a prolonged injection duration, was 
41 fuel temperature on the injection dynamics (stationary mass flow rate, injection delay, and valve opening/closing slope of the mass flow rate) of a ballistic injector, with special attention paid to the needle valve opening and closing stages. They indicated that the temperature had a huge influence on the valve opening delay. In a further study to extend insights into the injector dynamics, Payri et al. [29] developed a one-dimensional model and paid special attentions to the pressure drop in the control chamber, the viscous friction and the needle lifts. These studies investigated the injection dynamic with different fuels or different fuel temperatures and pressures, yet the impact of each fuel property on the injector dynamic response is still not clearly identified. Boudy et al. [30] investigated the influence of the properties of a biodiesel fuel on the injection process; in this study, the fuel density, bulk modulus and absolute viscosity were examined individually in both single- and triple-injection situations. He pointed out that density is one of the most influential fuel properties on the injection process. Han et al. [31] investigated the isolated effect of the fuel density, viscosity and bulk modulus on the injection mass and pressure propagation waves under split injection strategy conditions. They indicated that the fuel density and bulk modulus have a larger impact than the viscosity on the injection mass and pressure propagation. However, in these studies, the fuel properties varied only slightly, and the dynamic response, such as the needle valve opening/closing delay and opening/closing time, was not in their interests.

One-dimensional (1D) models are efficient and practical for predicting the performance of electronic fuel injectors, and have been adopted by many studies. For example, a 1D model of a solenoid-driven common rail ballistic injector was built by Payri et al. [32] to study the influences of the inlet fuel temperature on the injection rate. Ando et al. [33] investigated the magnetic aftereffect on the dynamic response of a fuel injector by building a simple and high accurate 1D simulation model. They indicated that a significant delay was caused by a lower 
maximum activation current, which generated a smaller magnetic force than a higher maximum

66

67

68

69 activation current. Another 1D model was built by Seykens et al. [34] to investigate the elasticity and nonlinearities of the injector needle valve. Additionally, 1D hydraulic models were also established by Han et al. [31] and Rahim et al. [35]. The detailed modelling of fuel injectors was demonstrated by Bianchi et al. [36], Payri et al. [32, 37] and Salvador et al. [38].

In this paper, the effects of three fuel properties (the fuel density, bulk modulus and absolute viscosity) on the valve opening/closing delay and the valve opening/closing time were carefully investigated. Firstly, an electronic fuel injector model was built according to Payri et al. [37] and completely validated by the experimental data disclosed in that article. Then, this validated injector model was included in a DOE model, where a Uniform Latin Hypercube method was adopted. Then, the effects of these fuel properties on the injector dynamic response were compared and shown by RSM function charts from a statistical point of view, in which an SSANOVA method was adopted.

DOE is a systematic method for building a relationship between the input factors and output factors of a process. A great deal of information can be obtained through a reduced number of DOE simulations; therefore, it is effective to investigate the influences of individual variables on the response. In DOE, "factors" refer to design variables, and "level" refers to a specific value assigned to a factor. A DOE method creates a number of design points, which is a variation in the selected model's parameters [39].

The ULH is one of the most commonly used DOE methods. In it, the design space of each factor or design parameter is divided into $n$ uniform levels. On each level of every factor, only one design point is placed. For each factor, $n$ ! permutations of the $n$ levels are possible. The design matrix of the ULH consists of one column for each factor, which is determined by a 
randomly chosen permutation of the $n$ levels. For a row of the design matrix, $n^{k}$ combinations are possible and have an equal chance of occurring. As the matrix is generated randomly, a correlation between the columns may exist [40].

The RSM is frequently used as a tool for building an approximation model based on the data generated through DOE [41]. Several methods can be adopted to build this model, such as polynomials, SS-ANOVA, NN, k-nearest, etc. SS-ANOVA is a statistical modelling algorithm based on a function decomposition similar to the classical analysis of variance (ANOVA) decomposition and the associated notions of main eff ect and interaction. It belongs to the family of nonparametric or semi-parametric models and shows some peculiarities such as the interpretability of the results, which distinguishes from the classical set of standard parametric models (polynomial models, etc.). It is suitable for both univariate and multivariate modelling/regression problems [42]. The SS-ANOVA [43] was adopted here for data analysis.

\section{The injector model and its validation}

The injector model can be built either by a set of ordinary differential equations or some advanced tools, i.e., Hydsim and AMESim software. Here, the fuel injector model was built in AMEsim software, as shown in Fig. 1. The model consisted of three different parts: the injector holder, the electro-valve and the nozzle. Each of its internal elements were geometrically characterised by using a silicone moulding technique [44] together with Scanning Electron Microscopy (SEM) images. The silicone moulding technique has been proven to be an accurate and useful tool for obtaining the geometry of different components. In addition, the hydraulic characteristic of some most important orifices, i.e. the control oil inlet/outlet orifices, and the nozzle orifices, were tested in purpose-made test rigs [37,38]. In this model, some assumptions were made: (1) all the variations are isothermal; and so, the fuel temperature and the fuel 
111 properties were assumed to be constant along the injector and equal to those at the injector inlet

112 [32]; (2) the pressure feeding the model is constant; therefore, it ignores the pressure

113 fluctuations caused by the cyclical oil supply from the high-pressure pumps.

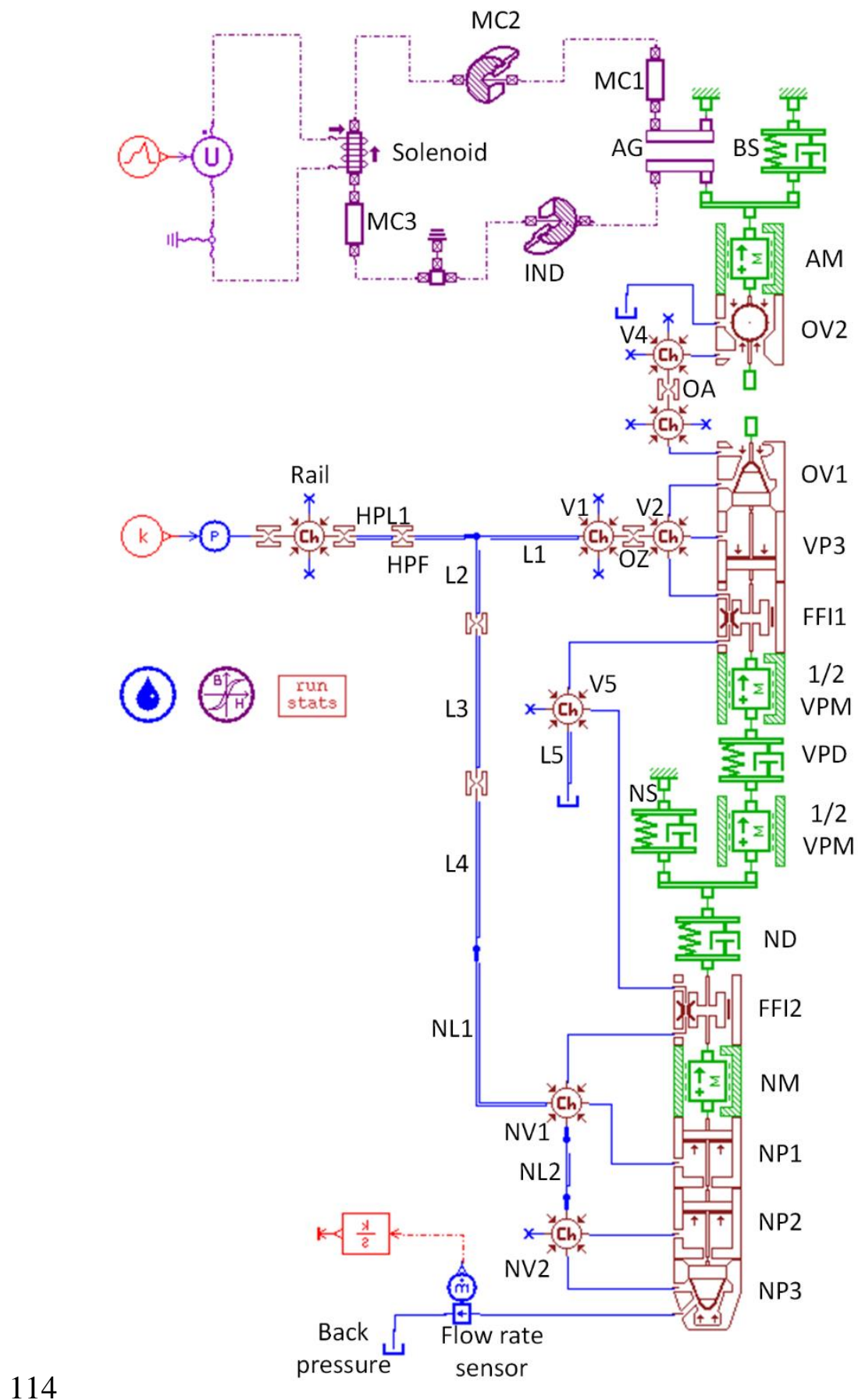

115 Fig. 1 One-dimensional fuel injector model 
116 The model was validated by the experimental injection rate and injection quantities of $30 \mathrm{MPa}$,

$11780 \mathrm{MPa}$ and $130 \mathrm{MPa}$ rail pressures. Three different activation times, i.e., $0.5 \mathrm{~ms}, 1 \mathrm{~ms}$ and 2

$118 \mathrm{~ms}$, were applied. The comparisons of the injection rate and the injection quantity are shown

119 in Fig. 2 and Fig. 3 respectively. Detailed values of the injection quantity are shown in Table

120 1. From Fig. 2, the simulation injection rates show an identical tendency at the end of needle

121 valve closing are much lower than the experimental results. This can be attributed to the elastic

122 differences in the material between an injector model and an authentic fuel injector. The

123 authentic fuel injector has an elastic body. Thus, when the injector is deactivated, the needle

124 valve moves back to its original place and hits on the seat. The needle valve bounces back

125 several times before it closes completely, which results in a small fuel injection rate in the

126 experimental results. In Fig. 3, it can be seen that there is a small difference between the

127 simulation results and experimental results, which becomes larger with an increase in the rail

128 pressure. This is because a high rail pressure leads to a larger flow speed. When the cross-

129 section area of the nozzle orifice is the same, a larger flow speed results in a larger injection

130 quantity. However, these tiny differences in the injection rate and injection quantity can hardly

131 have an impact on the injector dynamic response (opening/closing delay and opening/closing

132 time), which are mainly decided by the injection rate slopes. Fig. 2 indicates that the injection

133 rate slopes in all the sub-figures present a highly accurate reproduction of the experimental

134 injection rate. Therefore, the injector model is precise enough and can be used for further study.

135 For the detailed parameters of the injector model and the experimental data, refer to Payri et al.

136 [37]. 

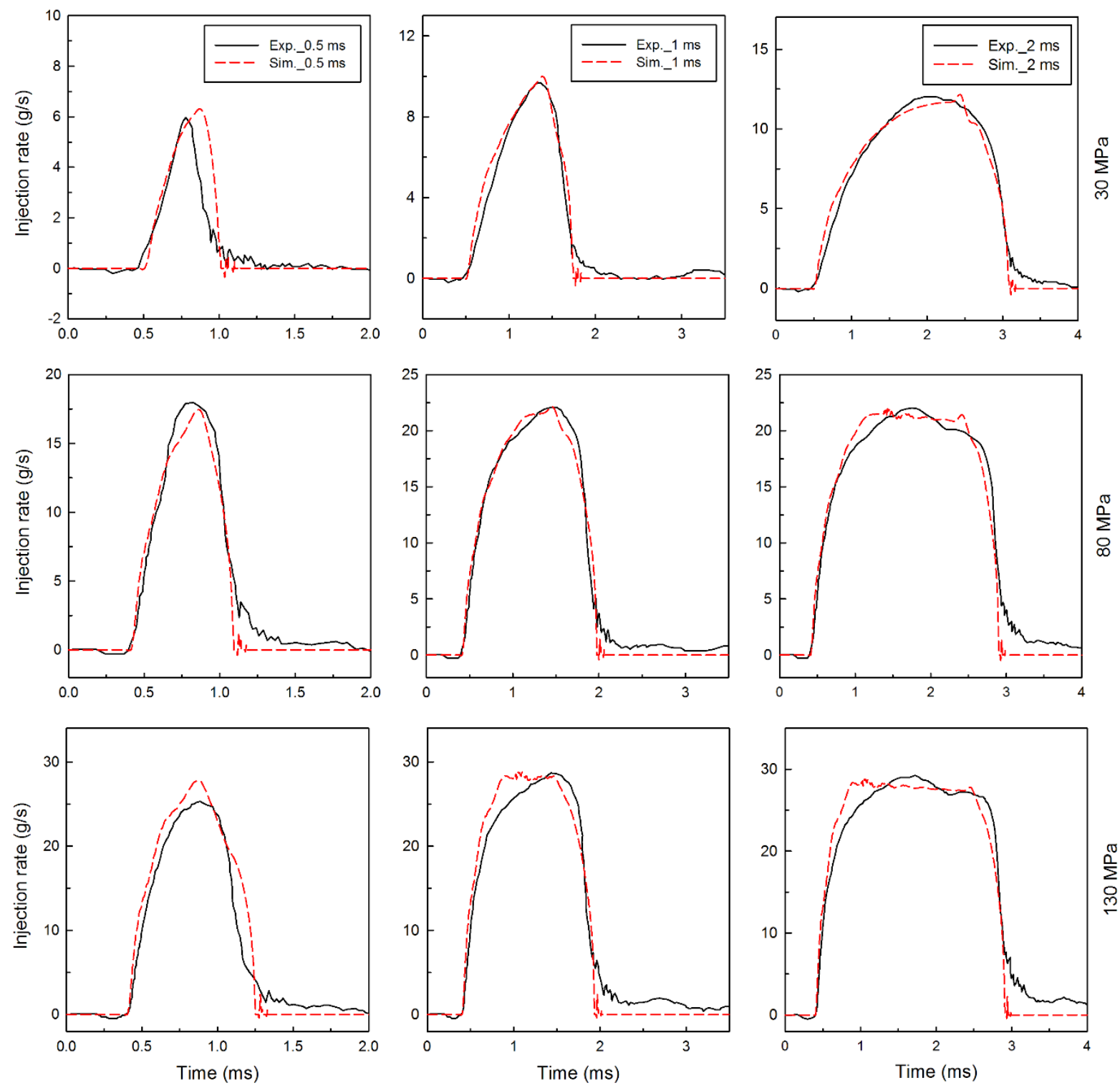

138 Fig. 2 Comparison of the injection rate under varies activation times and rail pressures 


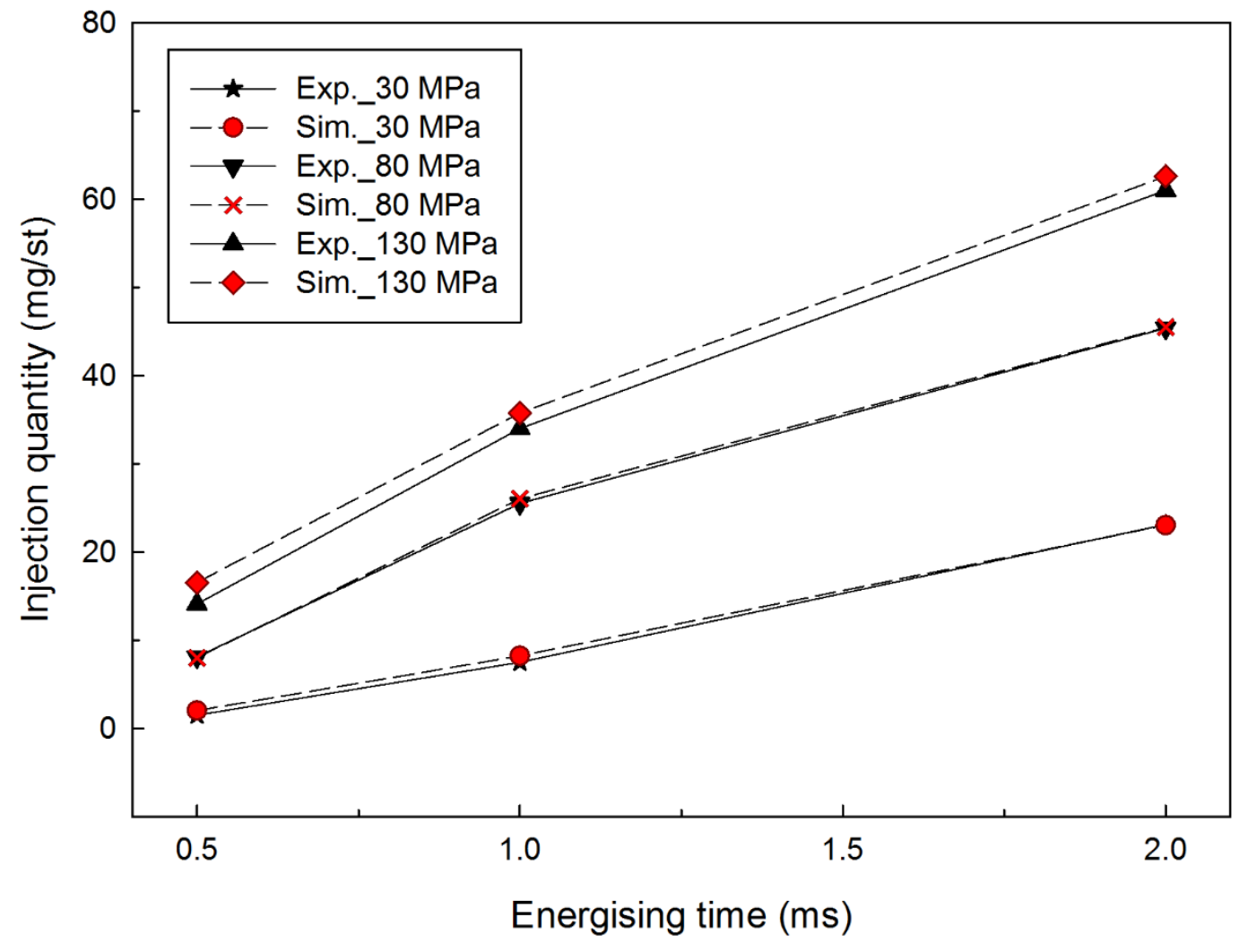

140 Fig. 3 Comparisons of the injection quantity under varies activation times and rail pressures

141 Table 1 Experimental and simulation injection quantity

\begin{tabular}{llllllc}
\hline Pressure & \multicolumn{2}{c}{$30 \mathrm{MPa}$} & \multicolumn{2}{c}{$80 \mathrm{MPa}$} & \multicolumn{2}{c}{$130 \mathrm{MPa}$} \\
Activate time & Exp., mg/st & Sim., mg/st & Exp., mg/st & Sim., mg/st & Exp., mg/st & Sim., mg/st \\
\hline $0.5 \mathrm{~ms}$ & 1.5 & 2.0 & 8.1 & 8.0 & 14.1 & 16.5 \\
$1.0 \mathrm{~ms}$ & 7.5 & 8.2 & 25.5 & 26.0 & 34.0 & 35.8 \\
$2.0 \mathrm{~ms}$ & 23.1 & 23.0 & 45.4 & 45.5 & 61.0 & 62.6 \\
\hline
\end{tabular}


143 3.1. Definition of the injector dynamic response

144 The injector dynamic response refers to the needle valve opening/closing delay and needle

145 valve opening/closing time, as shown in Fig. 4. The valve opening delay is defined as $\Delta \mathrm{T} 1$,

146 which is from the moment of $\mathrm{t} 1$ to the moment of $\mathrm{T} 1$; the valve opening time is defined as $\Delta$

$147 \mathrm{~T} 2$, which is from the moment of $\mathrm{T} 1$ to the moment of $\mathrm{T} 2$; the valve closing delay is defined

148 as $\Delta \mathrm{T} 3$, which is from the moment of $\mathrm{t} 3$ to the moment of $\mathrm{T} 3$; and the valve closing time is

149 defined as $\Delta \mathrm{T} 4$, which is from the moment of T3 to the moment of T4.

150

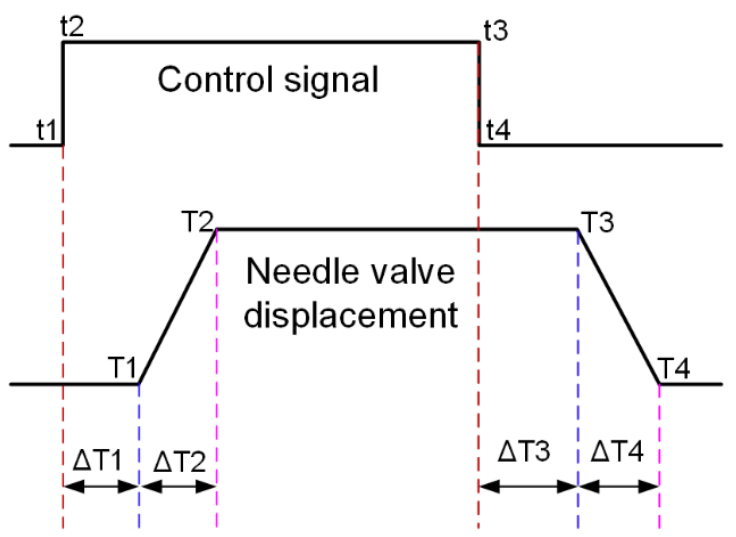

151 t1: the control signal initiates; $\mathrm{t} 2$ : the control signal reaches its maximum amplitude; $\mathrm{t} 3$ : the control signal begins

152 to de-activate; t4: the control signal has fully disappeared; T1: the needle valve starts to open; T2: the needle valve has reached its maximum displacement; T3: the needle valve begins to close; T4: the needle valve has fully closed.

154 Fig. 4 Schematic diagram of the definition of the dynamic response

155 The injector dynamic response will simply be represented by a limited delay integrator transfer 156 function: 
158 Where: $T$ is the time constant; $s$ is the field; $\tau$ is the delay.

\subsection{DOE model}

160 A DOE model was built within the modeFRONTIER software for investigating the effects of

161 fuel properties on the dynamic response, as shown in Fig. 5. Firstly, a uniform Latin hypercube

162 method was adopted in the DOE type for generating DOE designs, totally 1000 designs were

163 generated. Then, the fuel injector model was included in the AMESim node. The control signal

164 and the needle valve displacements generated by the fuel injector model were firstly written

165 into a text file, and to do this, appropriate writing and reading rules needed to be specified. The

166 text file is read by the MATLAB code, where the control signal opening/closing moments (t1,

$167 \mathrm{t} 2, \mathrm{t} 3$ and $\mathrm{t} 4)$ and the needle valve opening/closing moments (T1, T2, T3 and T4) are calculated

168 [45]. Therefore, the valve opening/closing delay and the valve opening/closing time can be

169 obtained. The simulation takes about 3 hours on an 8-core Intel i7-4790 CPU @ $3.60 \mathrm{GHz}$

170 computer. 


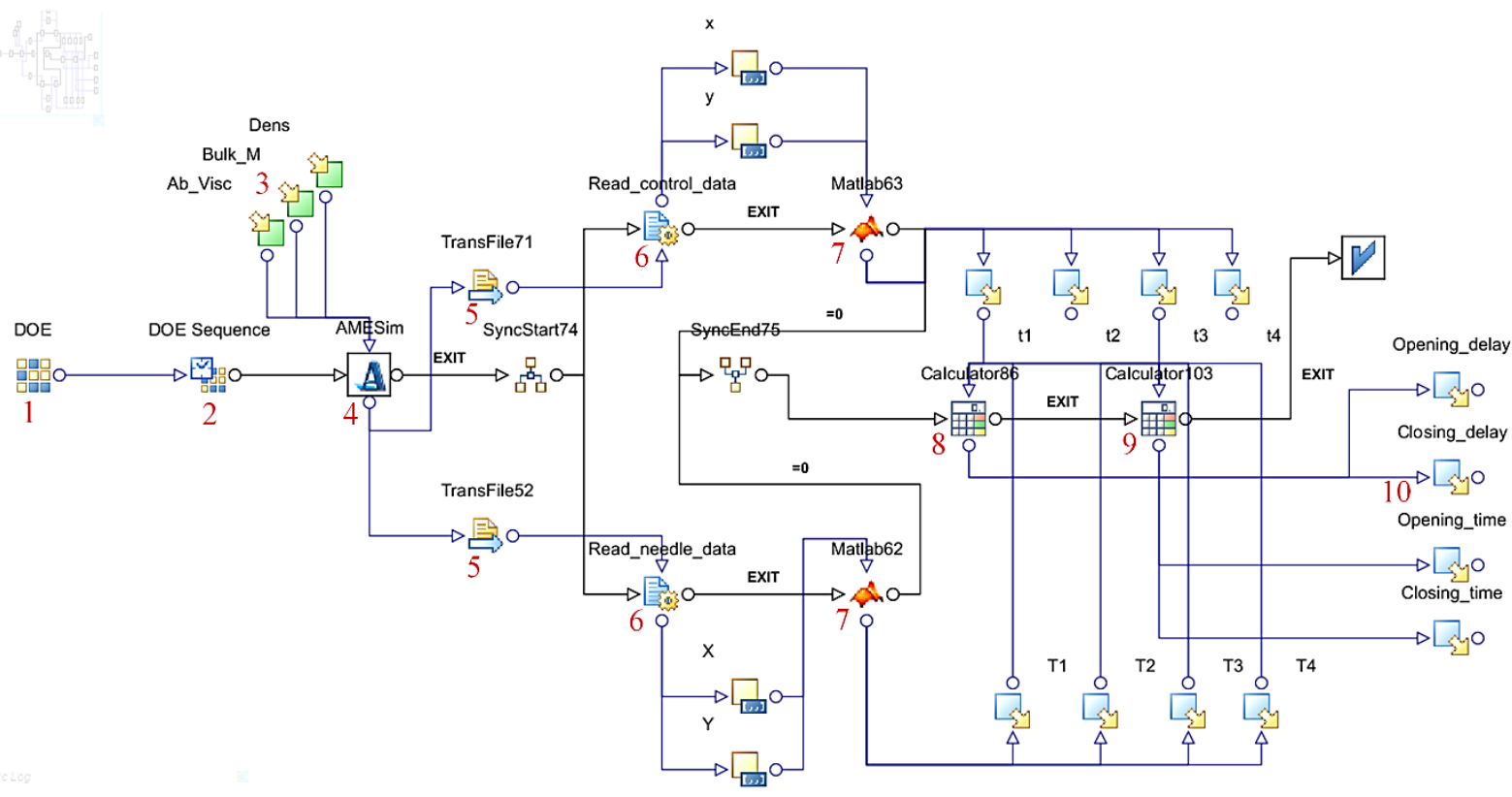

172 1: DOE designs generating; 2: DOE type selection; 3: Input parameters; 4: Fuel injector model; 5: Transfer the

173 control signal and needle valve displacement data synchronously; 6: Read the control signal and needle valve 174 displacement data from files respectively; 7: MATLAB codes; 8: Calculation of the valve opening/closing delay;

175 9: calculation of the valve opening/closing time; 10: Outputs.

176 Fig. 5 DOE model

\section{3.3. Boundaries and resolutions}

178 The boundaries of the three fuel properties derive from the Figure 2 of the reference [24]. In

179 that figure, the fuel properties of a stand winter diesel fuel are shown for a range of 0.1-300

$180 \mathrm{MPa}$ in pressure and $300-400 \mathrm{~K}$ in temperature. In the paper, the boundaries of a specific

181 pressure are set according to the minimum and the maximum values when the temperature

182 changes. Totally two pressures, including a low rail pressure (40 $\mathrm{MPa}$ ) and a high rail pressure

183 (200 MPa) were applied. The details of the boundaries are shown in Table 2.

184 Table 2 Fuel properties and their boundaries for DOE 


\begin{tabular}{llll}
\hline Input parameter & $40 \mathrm{MPa}$ & $200 \mathrm{MPa}$ & Step \\
\hline Dens, $\mathrm{kg} / \mathrm{mm}^{3}$ & $764-848$ & $860-920$ & 2 \\
Bulk_M, MPa & $1150-1950$ & $2750-3550$ & 20 \\
Ab_Visc, cP & $0.1-5.9$ & $2-46$ & 0.2 for $40 \mathrm{MPa}$, \\
& & & 0.5 for $200 \mathrm{MPa}$ \\
\hline
\end{tabular}

185

\section{Results and discussion}

\subsection{Sensitivity analysis}

187 The sensitivity of the three fuel properties on the dynamic response were compared at both the

188 low rail pressure and at high rail pressure, as shown in the left part and right part of Fig. 6, respectively. They were examined and obtained by using a first order SS-ANOVA algorithm.

190 From Fig. 6 (a) and (b), it can be seen that the bulk modulus plays a dominant role in

191 influencing the valve opening/closing delay at the low rail pressure. Interestingly, both the

192 density and the bulk modulus have an dominant effect on the valve opening/closing time; the

193 effects of the former are slightly larger than the latter, as shown in Fig. 6 (c) and (d). The bulk

194 modulus affects the fluid's incompressibility. A large bulk modulus indicates that a larger

195 pressure is needed to decrease the volume of a fluid. Therefore, a high incompressibility factor

196 is provided by a fuel with a large bulk modulus. The fuel's incompressibility is one of the

197 factors that affects the pressure wave's propagation speed and amplitude. Since the needle

198 valve and the solenoid valve are hydraulic connected. The effects of bulk modulus are

199 eventually reflected in the injector dynamic response. Density has an impact on the inertia

200 resistance and on the pressure wave propagation speed. Therefore, the density also profoundly

201 affects the dynamic response. The relationship of the bulk modulus and density with the speed

202 of sound is shown in equation(2): 
204 Where, $v$ is the speed of sound in the fluid; $B$ is the bulk modulus of the fluid; and $\rho$ is the 205 density of the fluid.

206 The right part of Fig. 6 indicates that the effects of the absolute viscosity and the bulk modulus

207 are influential on the dynamic response of the injector at the high pressure, and the former plays 208 a dominant role in the valve opening/closing time. This is because viscosity drastically 209 increases at high pressures. Viscosity is related to the friction force, which impedes the 210 movements of the needle valve. Since the fuel oil in the control chamber flows in a laminar 211 form. The pressure loss is proportional to the friction coefficient, fluid density and fluid velocity, 212 as shown in equation (3) [30]:

$$
\Delta P=C_{f} \frac{L}{D} \frac{\rho u^{2}}{2}
$$

214 Where, $C_{f}$ is the friction coefficient; $\rho$ is the fluid density, $\mathrm{kg} / \mathrm{m}^{\wedge} 3 ; u$ is the fluid velocity,

$215 \mathrm{~m} / \mathrm{s} ; L$ is the pipe length, $\mathrm{m} ; D$ is the pipe diameter, $\mathrm{m}$.

216 The friction coefficient of a fluid flow in laminar conditions can be calculated as:

$$
C_{f}=\frac{64}{R_{e}}=\frac{64 \mu}{\rho u D}
$$

218 Where, $\mu$ is the absolute viscosity, Pa.s; $R_{e}$ is the Reynolds number [46, 30]. 
219 From (4), it can be seen that the friction coefficient is proportional to the absolute viscosity.

220 Therefore, the absolute viscosity is also an influential factor and is significant to the injector 221 dynamic response. 
$40 \mathrm{MPa}$

(a) Opening delay

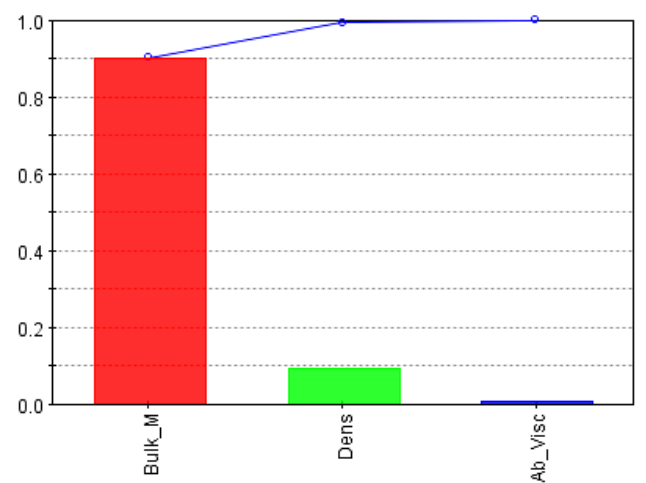

(b) Closing delay

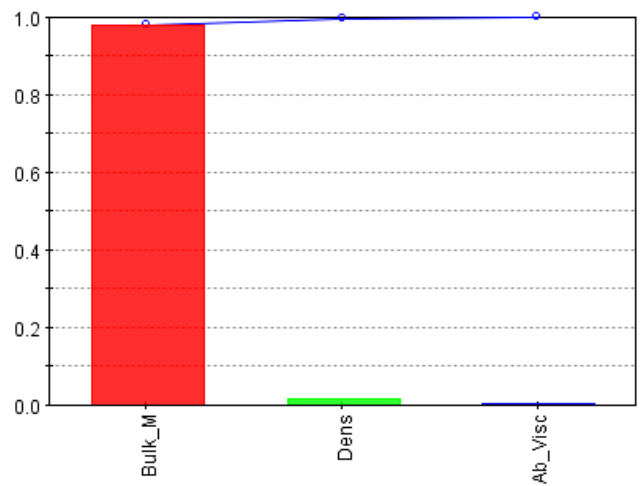

(c) Opening time

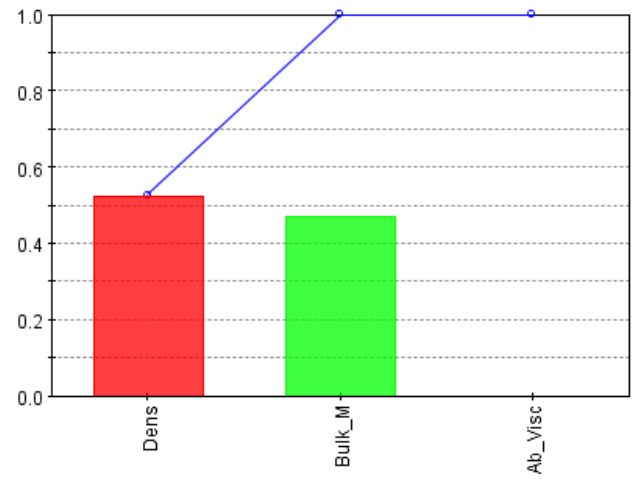

(d) Closing time

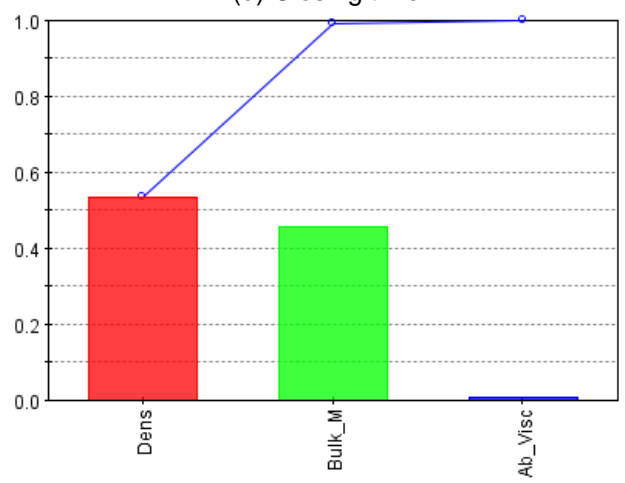

$200 \mathrm{MPa}$

(e) Opening delay

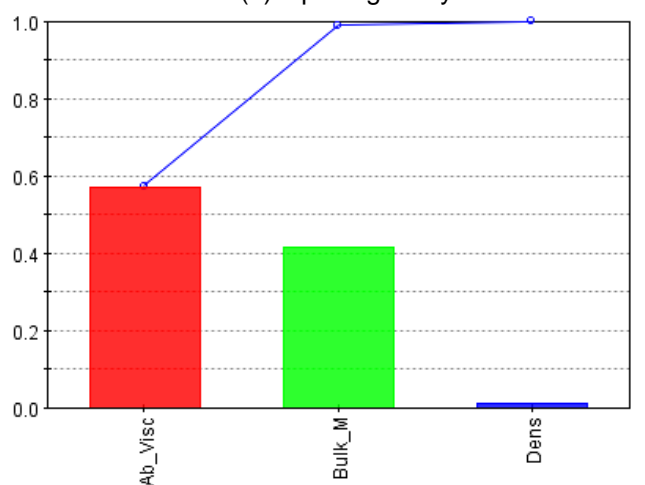

(f) Closing delay

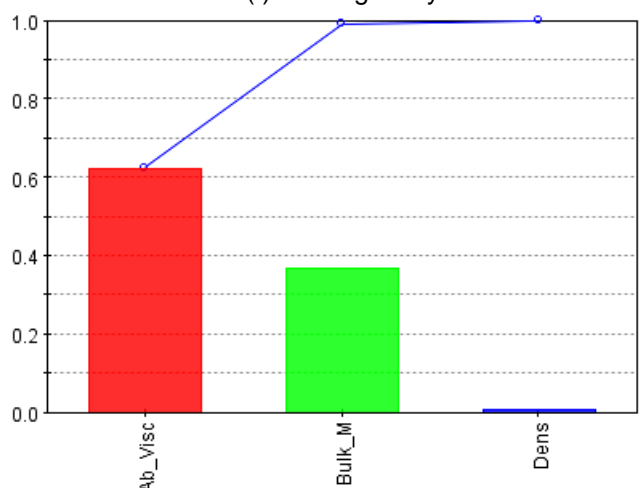

(g) Opening time

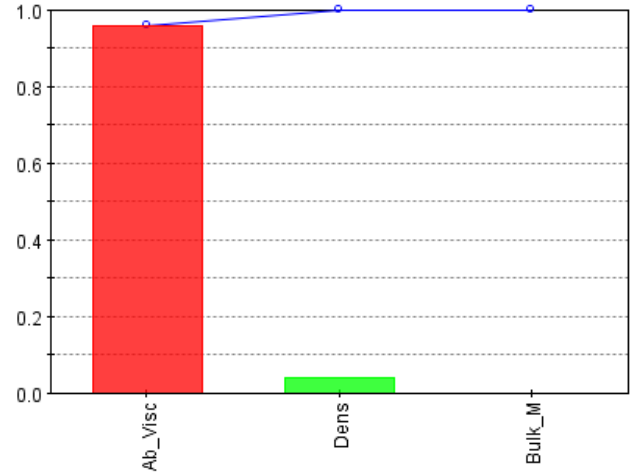

(h) Closing time

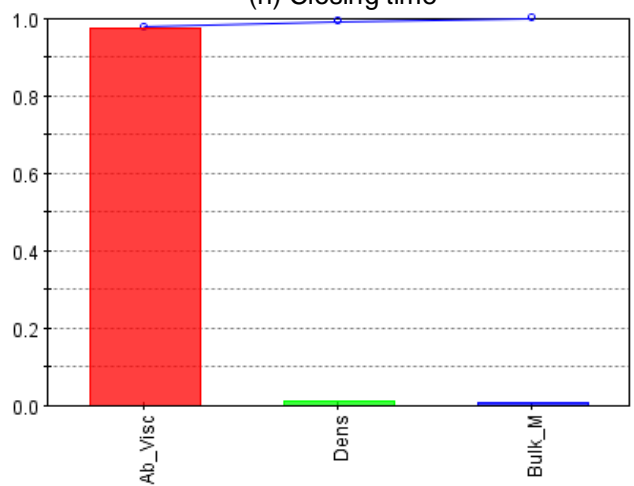

223 Fig. 6 Sensitivity of fuel properties on the injector dynamic response. (a) opening delay at 40 MPa rail pressure;

224 (b) closing delay at $40 \mathrm{MPa}$ rail pressure; (c) opening time at $40 \mathrm{MPa}$ rail pressure; (d) closing time at $40 \mathrm{MPa}$ 

time at $200 \mathrm{MPa}$ rail pressure; (h) closing time at $200 \mathrm{MPa}$ rail pressure.

227 The effects of the bulk modulus, density and absolute viscosity on the dynamic response are 228 shown in Fig. 8, Fig. 14 and Fig. 19 respectively. They were generated by the RSM function, with only one factor changing at a time.

\subsection{Effects of the bulk modulus}

231 The trends of the effects of the bulk modulus are identical at both the low and the high rail

232 pressures, as are the effects of the fuel density. Since the bulk modulus and the density were influential at the low pressure, only those effects are presented, as shown in Fig. 8, in which the effects are shown as red lines.

235 It is well known that the valve opening time and the valve closing time depend on the pressure difference between the control chamber and the accumulation chamber. Therefore, the

237 pressures in the control chamber and the accumulation chamber are shown in Fig. 9, and the

238 details of Section A and Section B are reported in Fig. 10 and Fig. 11, respectively. In these

239 figures, only three different values of the bulk modulus were reported in order to get a clear

240 view of the differences in the pressures. The pressures in the control chamber and the

241 accumulation chamber were drawn in thick lines and in thin lines respectively. The same colour

242 in a figure indicates the same value of factors. The above rules also apply to Fig. 14, Fig. 15,

243 Fig. 16, Fig. 19, Fig. 20 and Fig. 21.

244 In order to obtain a better understanding of the pressure fluctuation in the control chamber. A

245 theoretical pressure fluctuation prediction was given before the simulation pressure fluctuation 
246 was investigated. This is presented along with the displacements of the solenoid valve and the

247 needle valve opening/closing, as shown in Fig. 7. The pressure in the control chamber is

248 identical to the rail pressure $p_{r}$ before the solenoid valve is activated; when it is activated, it

249 leads to a continual pressure drop in the control chamber. When the pressure decreases to the

250 critical pressure $p_{c o}$, it triggers the needle valve to open. During this process, the pressure in

251 the control chamber increases slightly. However, the pressure drops again to a lower and steady

252 pressure when the needle valve and the solenoid valve are both fully opened. When the solenoid

253 valve is deactivated and fully closed, the pressure in the control chamber is regaining the rail

254 pressure to push the needle valve to close. During this period of time, the pressure in the control

255 chamber decreases slightly and then rockets up to the level of the rail pressure once the needle

256 valve is completely closed.

257

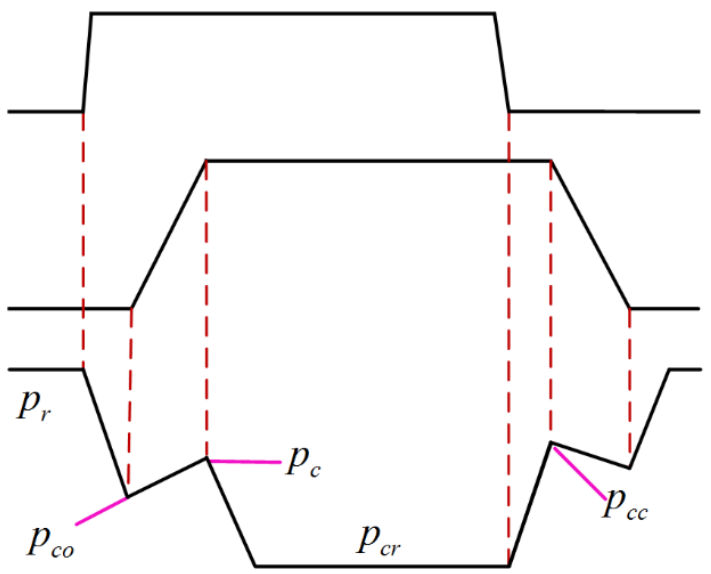

Solenoid valve

displacement

Needle valve

displacement

Pressure in the

control chamber

Fig. 7 Pressure change in the control chamber

259 From Fig. 8 (a) and (b), it can be seen that both the valve opening delay and the valve closing

260 delay decrease with an increase in the bulk modulus. From equation(2), it can be deduced that

261 the speed of sound through the fluid increases with an increase in the bulk modulus. A large

262 bulk modulus indicates a fast pressure wave propagation. This leads to an advanced pressure 
263 fluctuation. Therefore, the pressure in the control chamber drops faster when the solenoid valve

264 is activated than in a fluid with a small bulk modulus, as shown in Fig. 10; the fast pressure

265 wave propagation also results in a faster pressure rise when the solenoid is deactivated, as

266 shown in Fig. 11. In these conditions, a small valve opening delay and valve closing delay were

267 seen in the large bulk modulus case. In addition, Fig. 10 also indicates that the advanced

268 pressure fluctuation leads to a lower critical opening pressure $p_{c o}$, which would result in a larger

269 pressure difference at the early stage of the needle valve opening. As is stated above, a large

270 pressure difference is beneficial for a small valve opening delay; however, the large pressure

271 difference changed to a small one at the later stage of the needle valve opening, as shown in

272 the middle part of Fig. 9. A small pressure difference indicates a small force difference, which

273 provides a small net force to push the needle valve upwards when the solenoid is activated; this

274 leads to a slow needle movement, and thus a large valve opening time. In general, a large valve

275 opening time is due to a large bulk modulus, as shown in Fig. 8 (c). However, the small pressure

276 difference provides less resistance to the needle valve movements when the solenoid is

277 deactivated. Thus, a small valve closing time is seen, as shown in Fig. 8 (d). The needle valve

278 displacements under different bulk moduli are shown in Fig. 12. The needle valve opens earlier

279 but reaches its maximum position later in cases with a larger bulk modulus, as opposed to those

280 with a small bulk modulus. However, the needle valve closes and moves back to its original

281 place in advance. The results shown in Fig. 12 agree with those shown in Fig. 7. 
(a) Opening delay

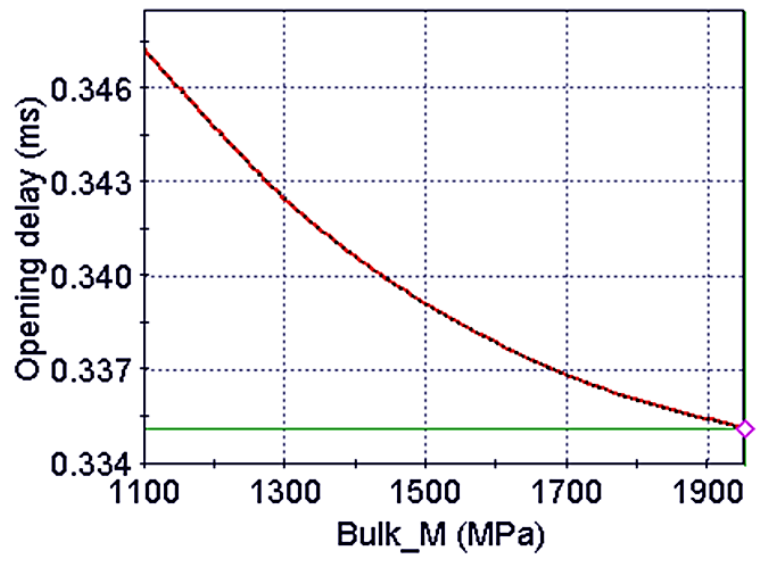

(c) Opening time

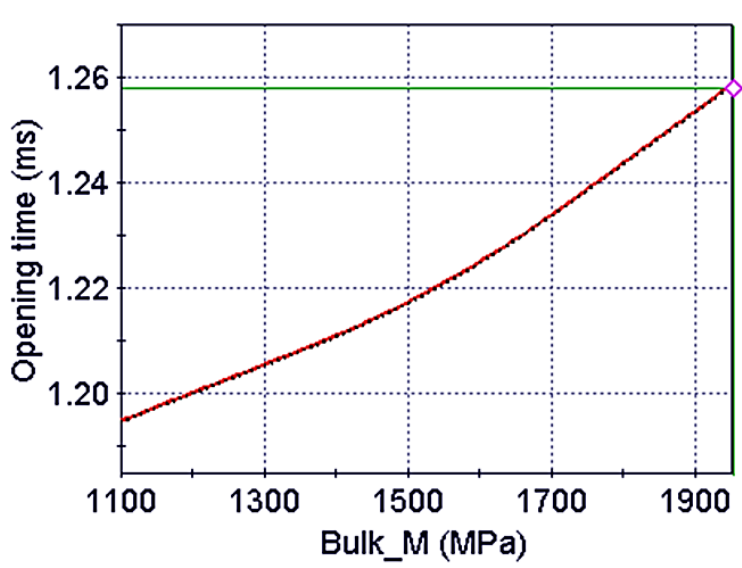

(b) Closing delay

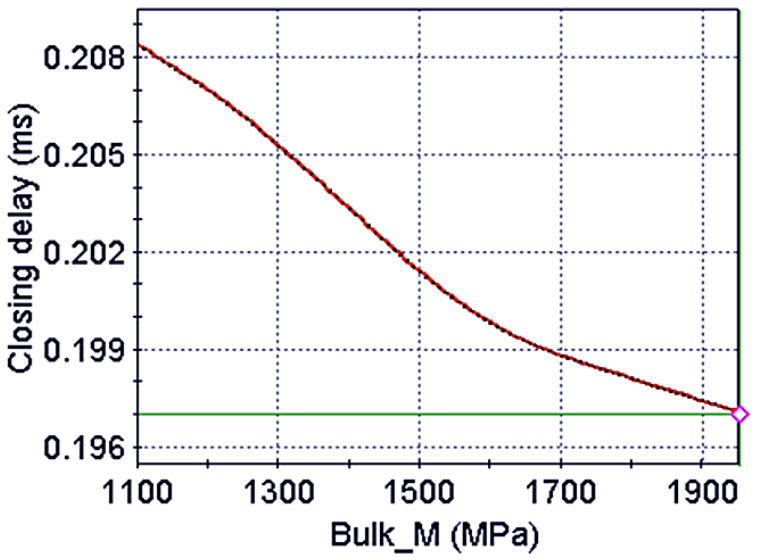

(d) Closing time

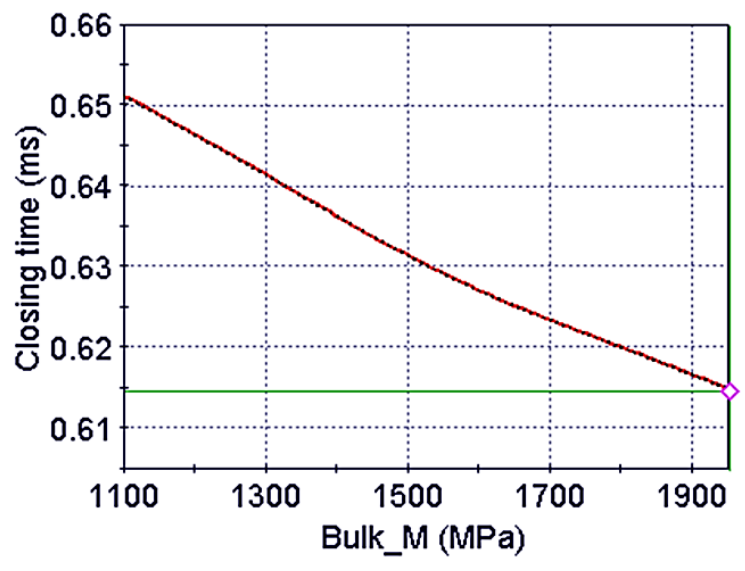




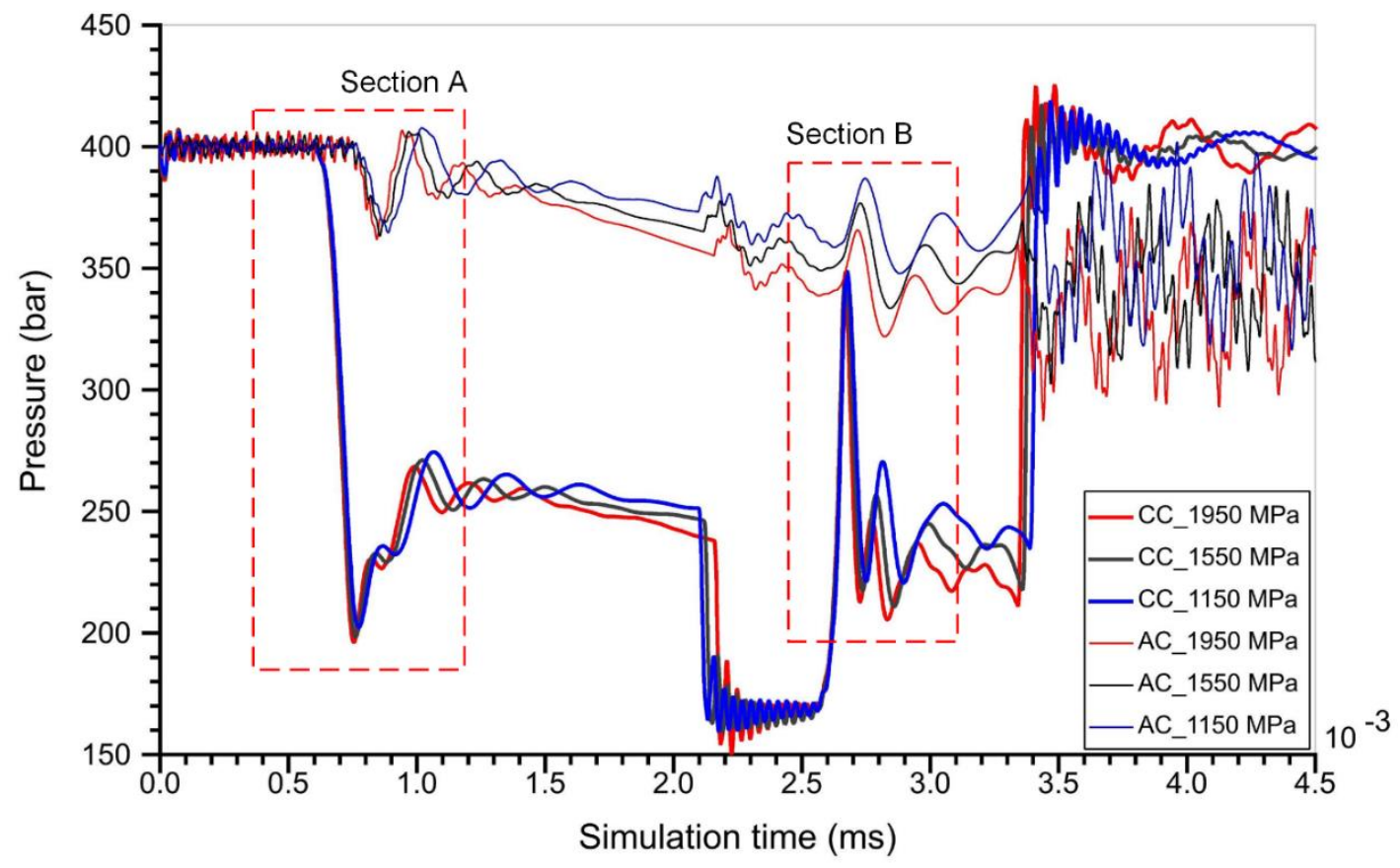

Fig. 9 Pressure in the control chamber and in the accumulation chamber at the low rail pressure

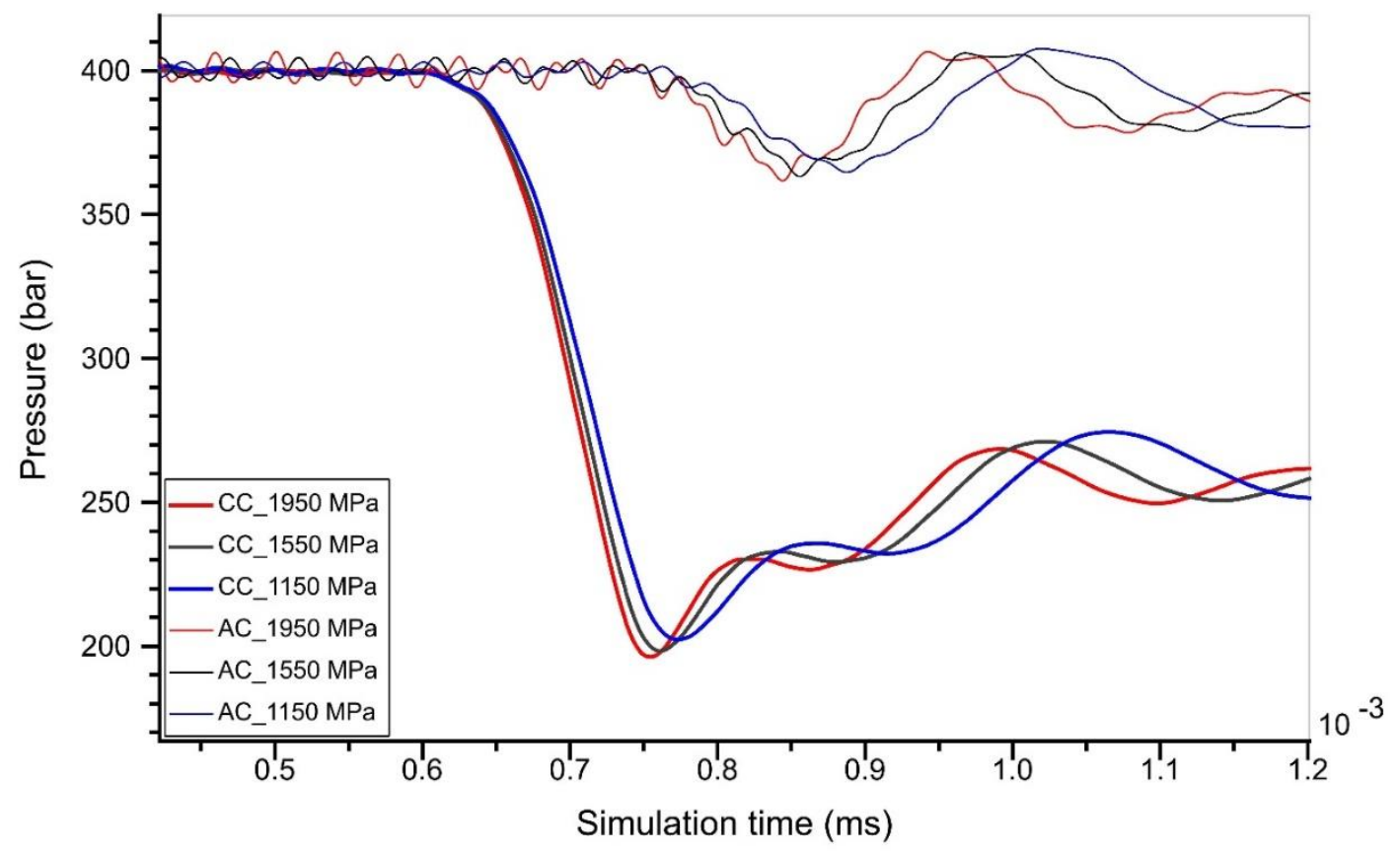

Fig. 10 Details of Section A in Fig. 9 


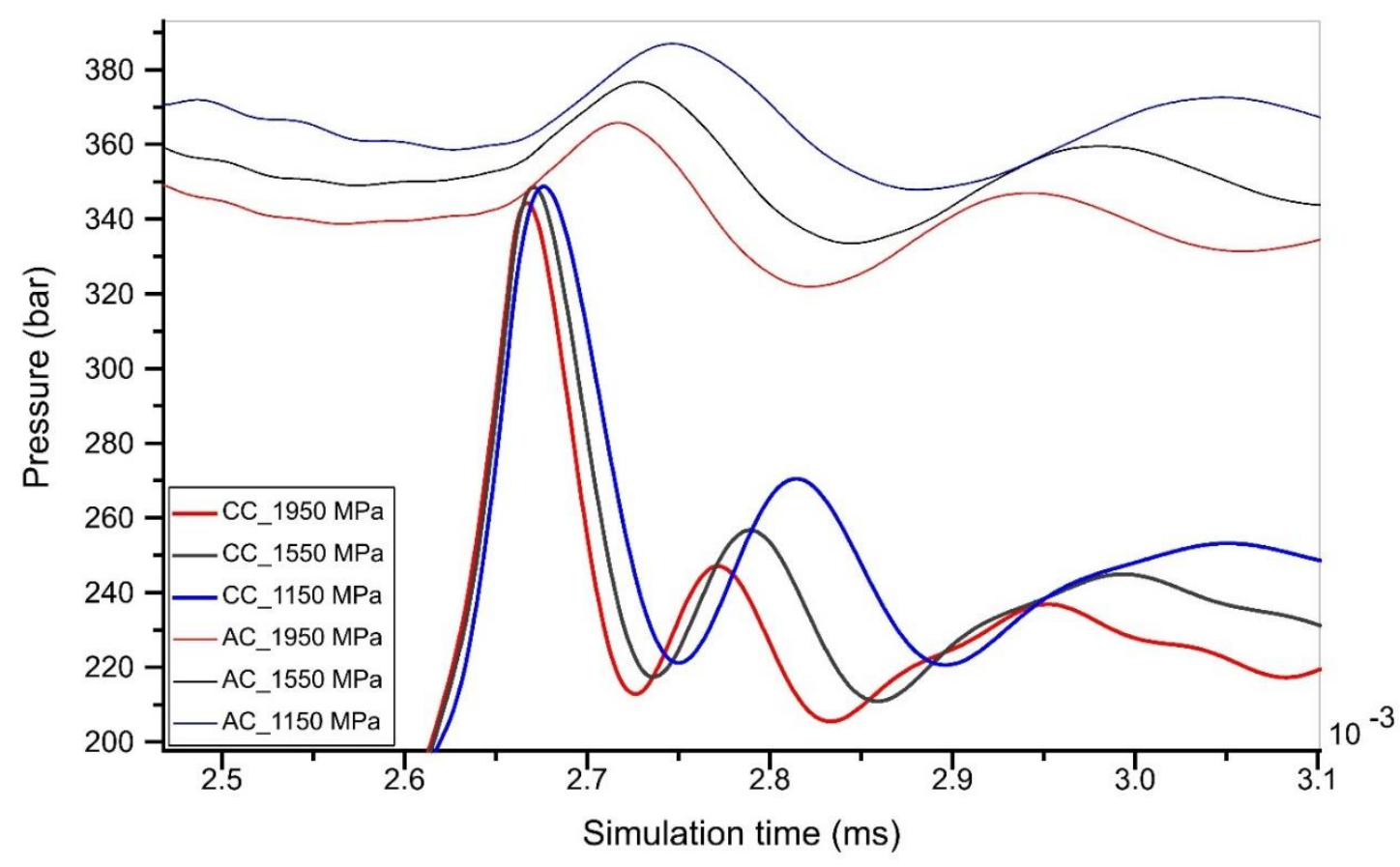

289 Fig. 11 Details of Section B of Fig. 9

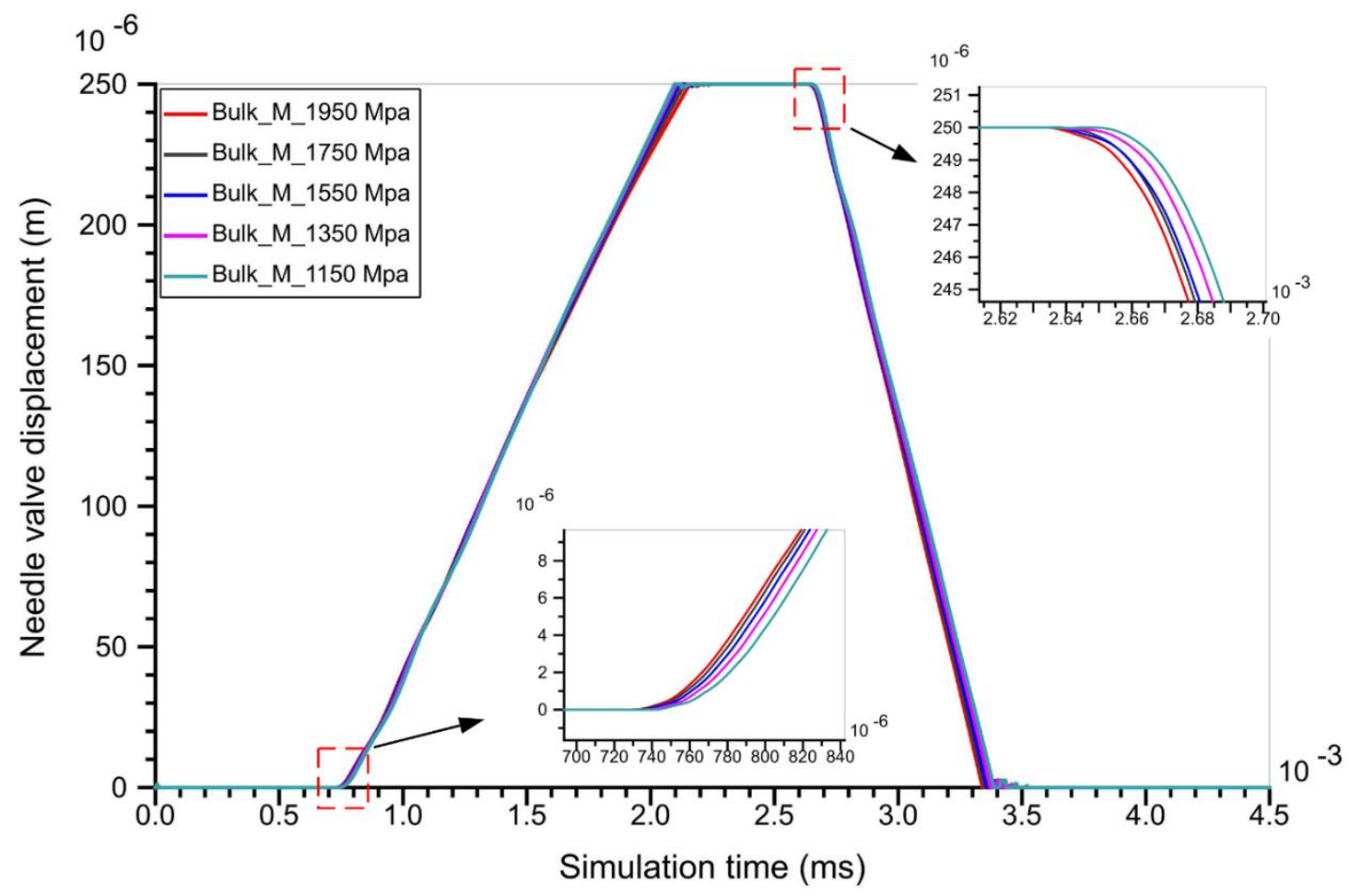

Fig. 12 Needle valve displacements under different bulk modulus conditions 


\subsection{Effects of the fuel density}

293 A high fuel density contributes to increasing the valve opening/closing delay and the valve

294 opening/closing time, as shown in Fig. 13. A high density indicates a large inertia; therefore, it

295 retards the pressure wave propagation (as shown in Fig. 15 and Fig. 16) and results in a large

296 resistance to the movements of the needle valve at both the valve opening and valve closing

297 stages (as shown in Fig. 17). The retarded pressure wave propagation leads to large hydraulic

298 delays (valve opening/closing delay), and the large inertia resistance is the main reason for the

299 increased valve opening/closing time in high-density conditions.

(a) Opening delay

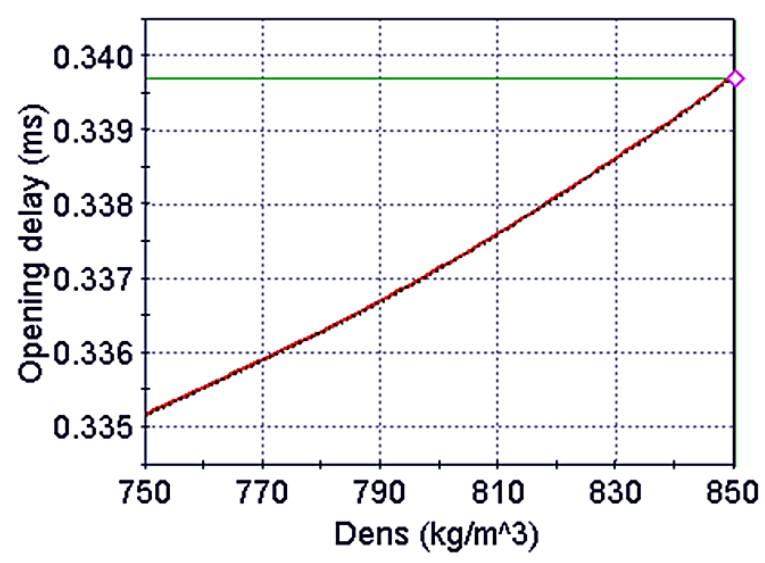

(c) Opening time

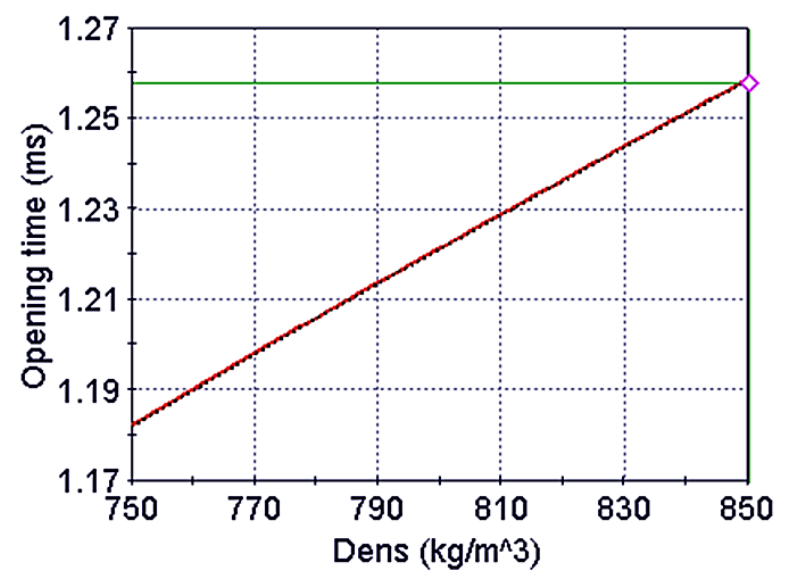

(b) Closing delay

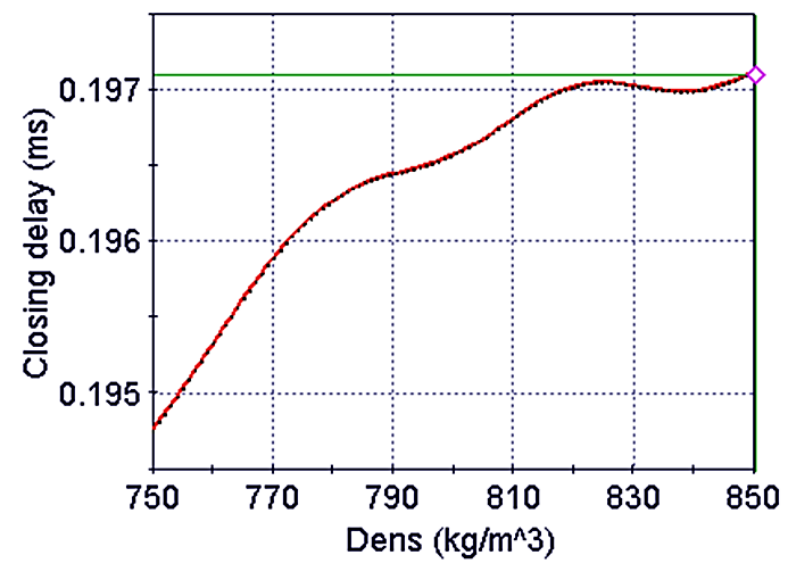

(d) Closing time

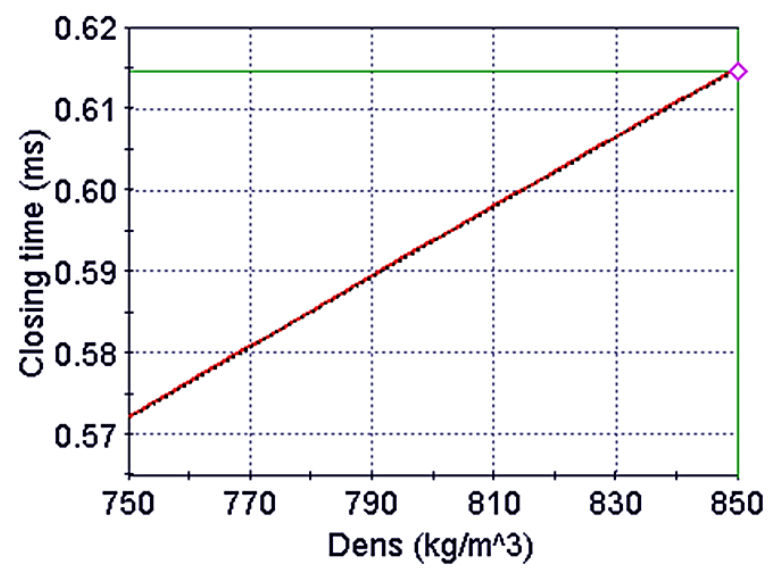

301 Fig. 13 Effects of the density on the dynamic response at $40 \mathrm{MPa}$ rail pressure 

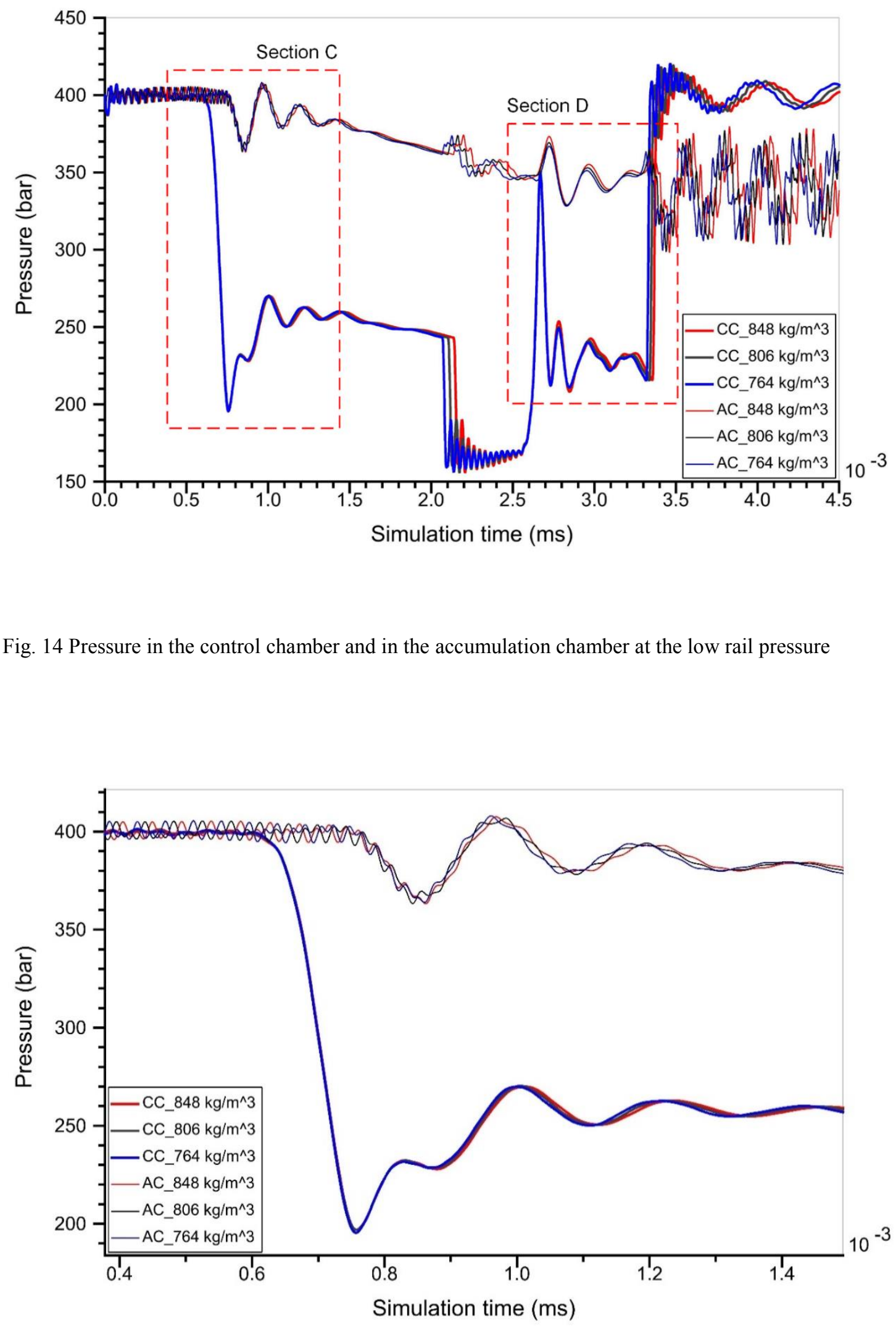


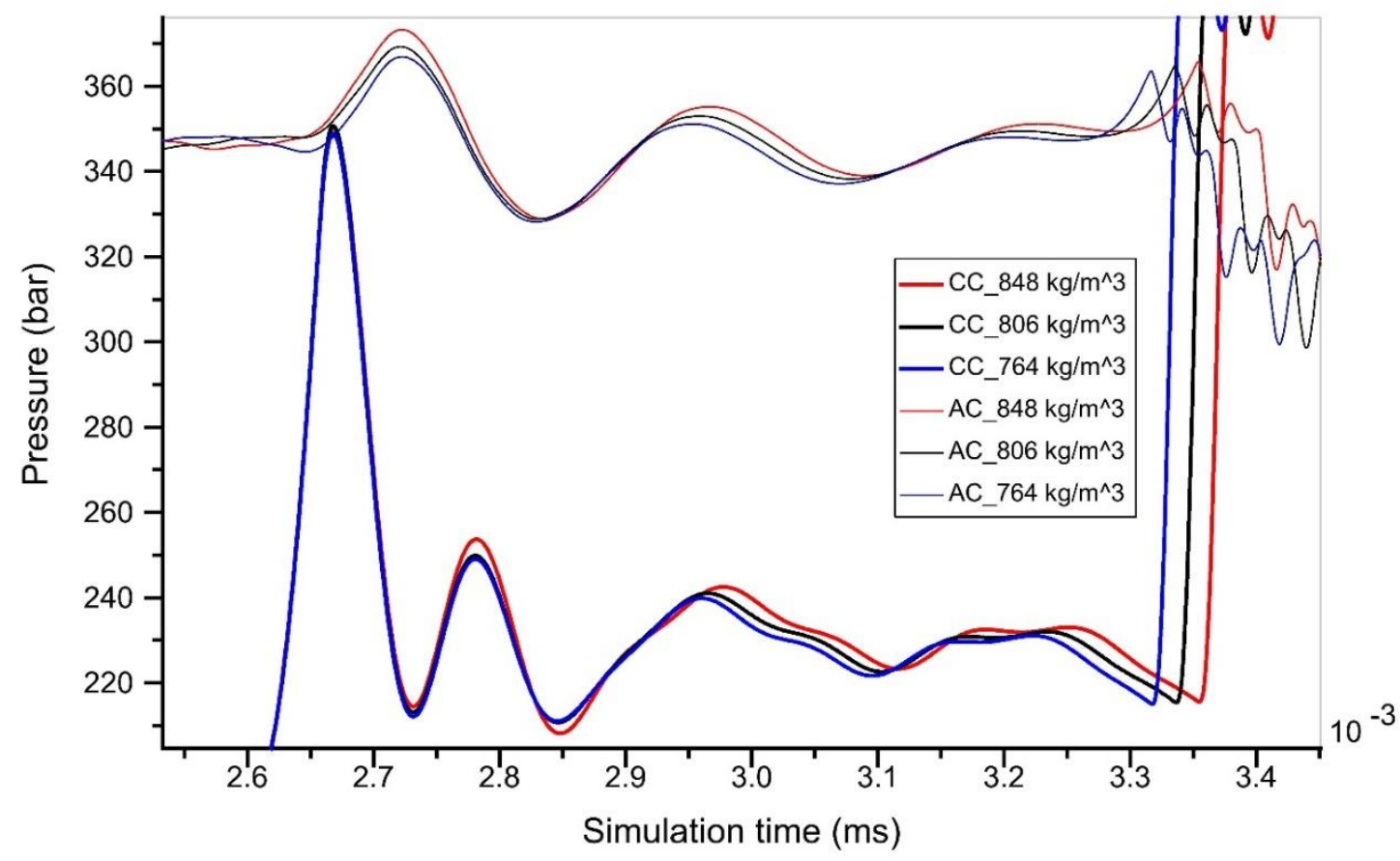

307 Fig. 16 Details of Section D in Fig. 14

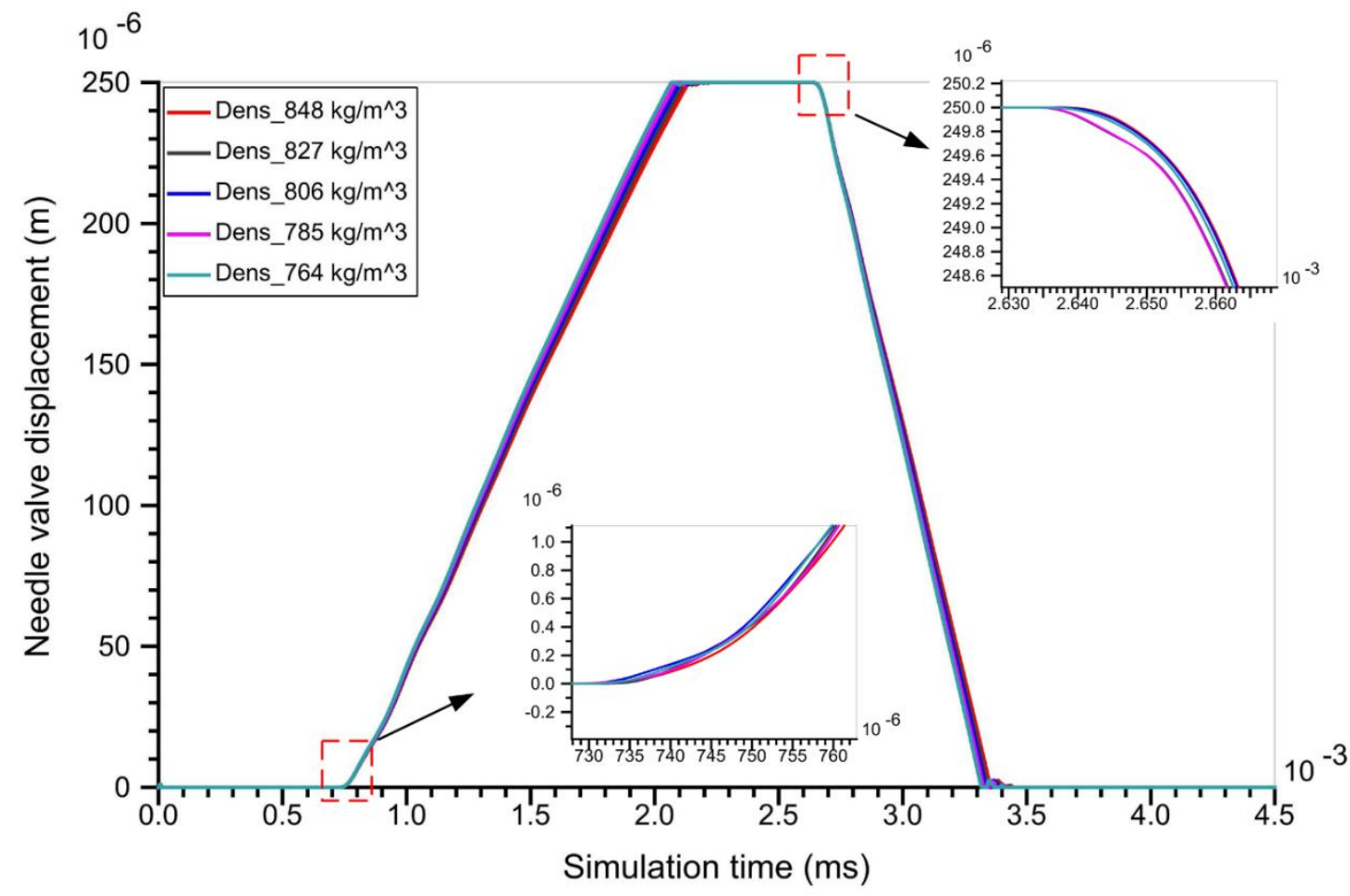

Fig. 17 Needle valve displacements in different fuel density conditions 


\subsection{Effects of the viscosity}

311 At the high rail pressure, the viscosity varies over a much bigger range with a change in

312 temperature, than at the low rail pressure. A high viscosity suppresses the amplitude of the

313 pressure wave and leads to a quick dampening rate [30]. In addition, from equations (3) and

314 (4), it can be inferred that a high viscosity results in a large pressure loss in the control chamber.

315 A quicker pressure wave dampening rate means the pressure in the control chamber reaches

316 the critical valve opening pressure in a shorter time when the solenoid is activated, as shown

317 in Fig. 20. Therefore, a high fuel viscosity results in a small valve opening delay, as shown in

318 Fig. 18 (a). A large pressure loss in the control chamber leads to a slightly lower steady pressure

319 when the needle valve is fully opened, as shown in Fig. 19. This lower steady pressure also

320 means that a larger pressure difference exists between the control chamber and the

321 accumulation chamber. As stated previously, the pressure difference plays a dominant role in

322 the valve opening and valve closing times. Although the friction force increases with the

323 increase in viscosity, the friction force is still not comparable to the force generated by the

324 pressure difference, as shown in Fig. 22. Therefore, a high viscosity generates a large pressure

325 difference, which accelerates the needle movement to achieve a short valve opening time at the

326 needle valve opening stage, and slows down the needle action when it is returning to its seat,

327 which results in a large valve closing time, as shown in Fig. 18 (c) and (d). Additionally, the

328 slightly lower steady pressure indicates that it takes a longer time to restore the critical valve

329 closing pressure. Therefore, a larger valve closing delay is seen, as shown in Fig. 18 (b).

330 Detailed needle movements are shown in Fig. 23. 
(a) Opening delay

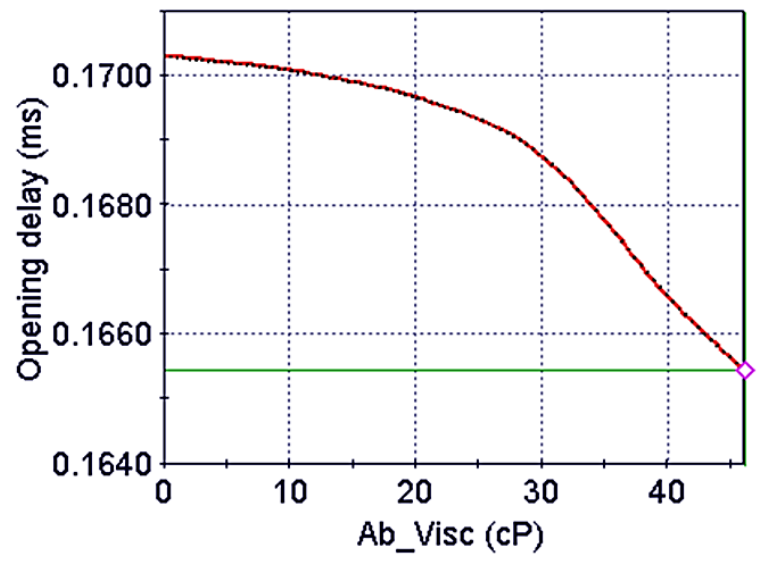

(c) Opening time

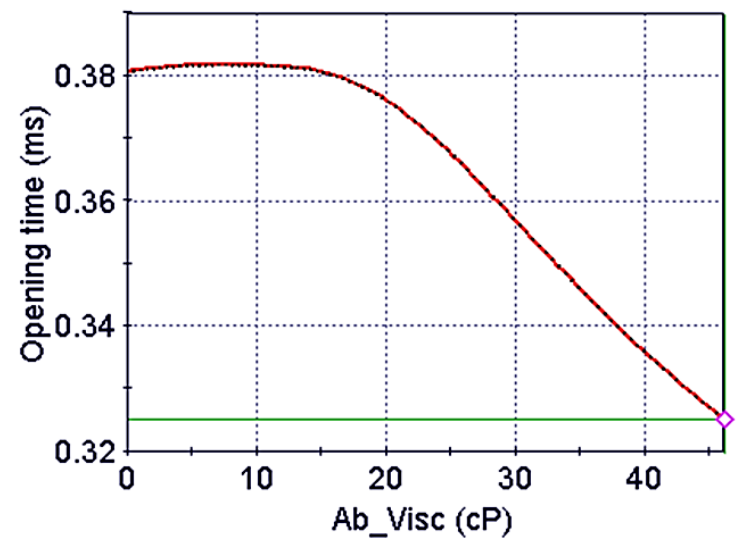

(b) Closing delay

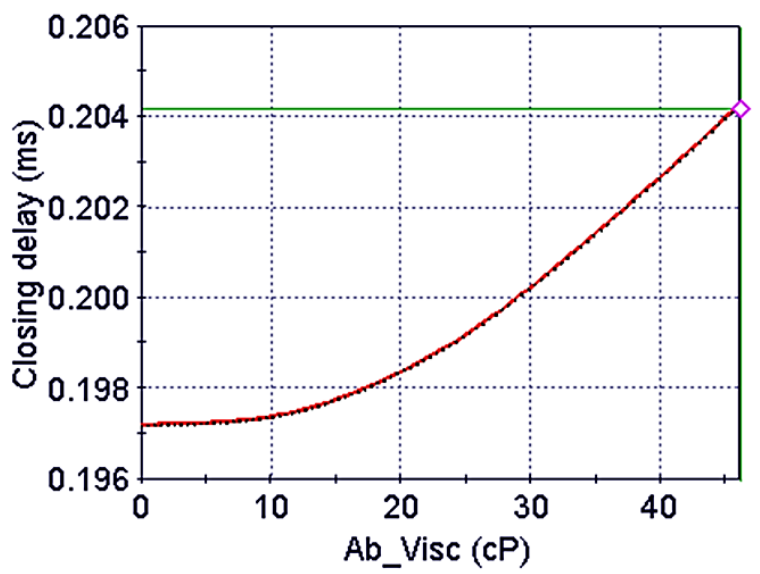

(d) Closing time

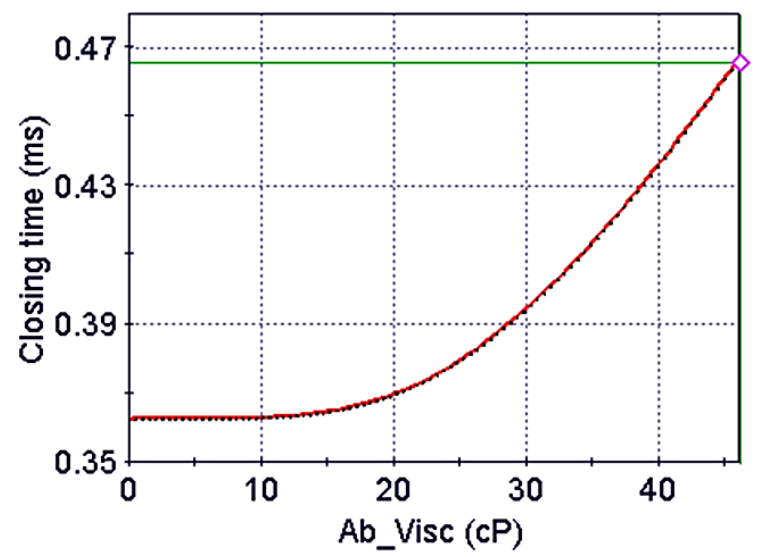

332 Fig. 18 Effects of the absolute viscosity on the dynamic response at $200 \mathrm{MPa}$ rail pressure 


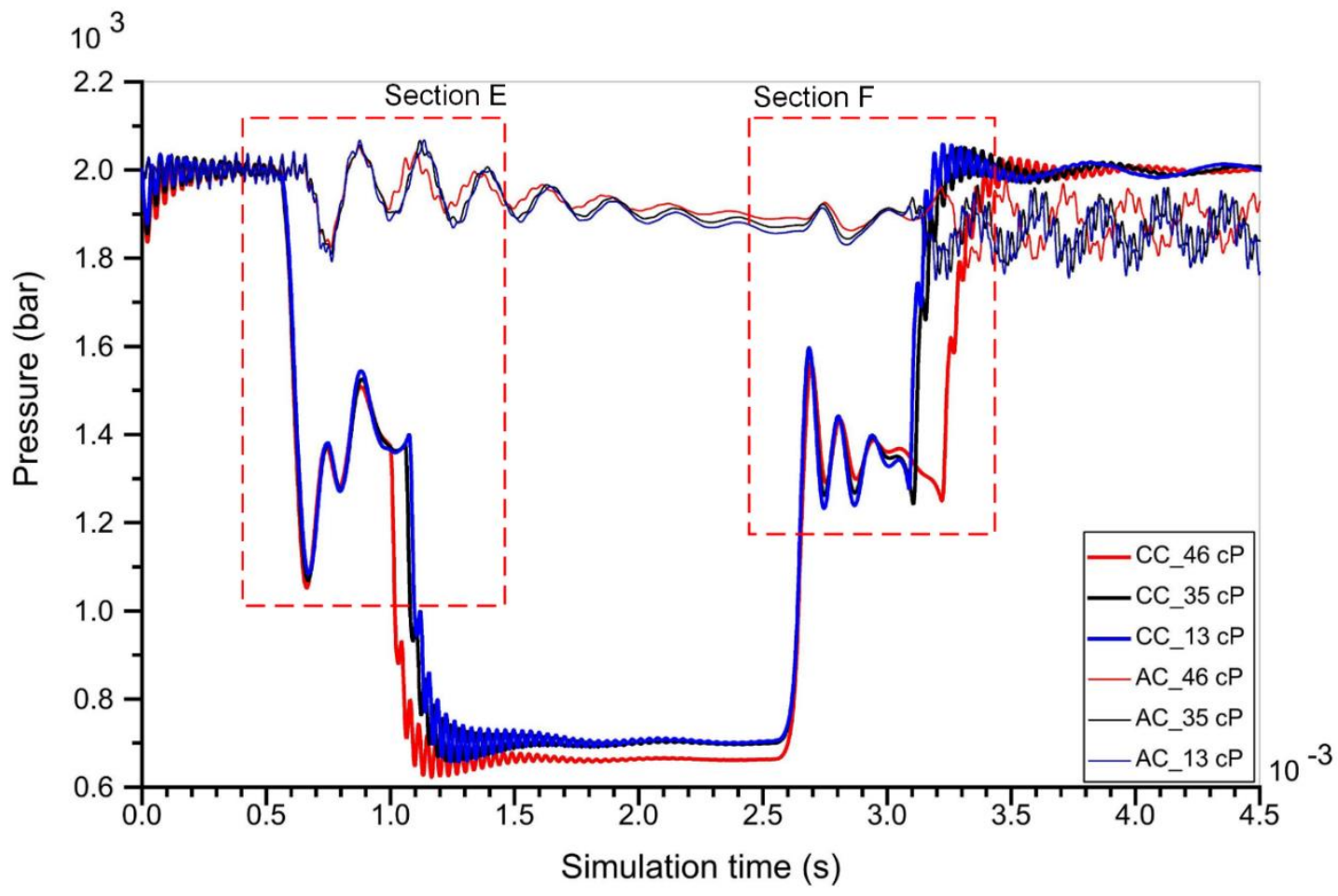

334 Fig. 19 Pressure in the control chamber and in the accumulation chamber at the high rail pressure

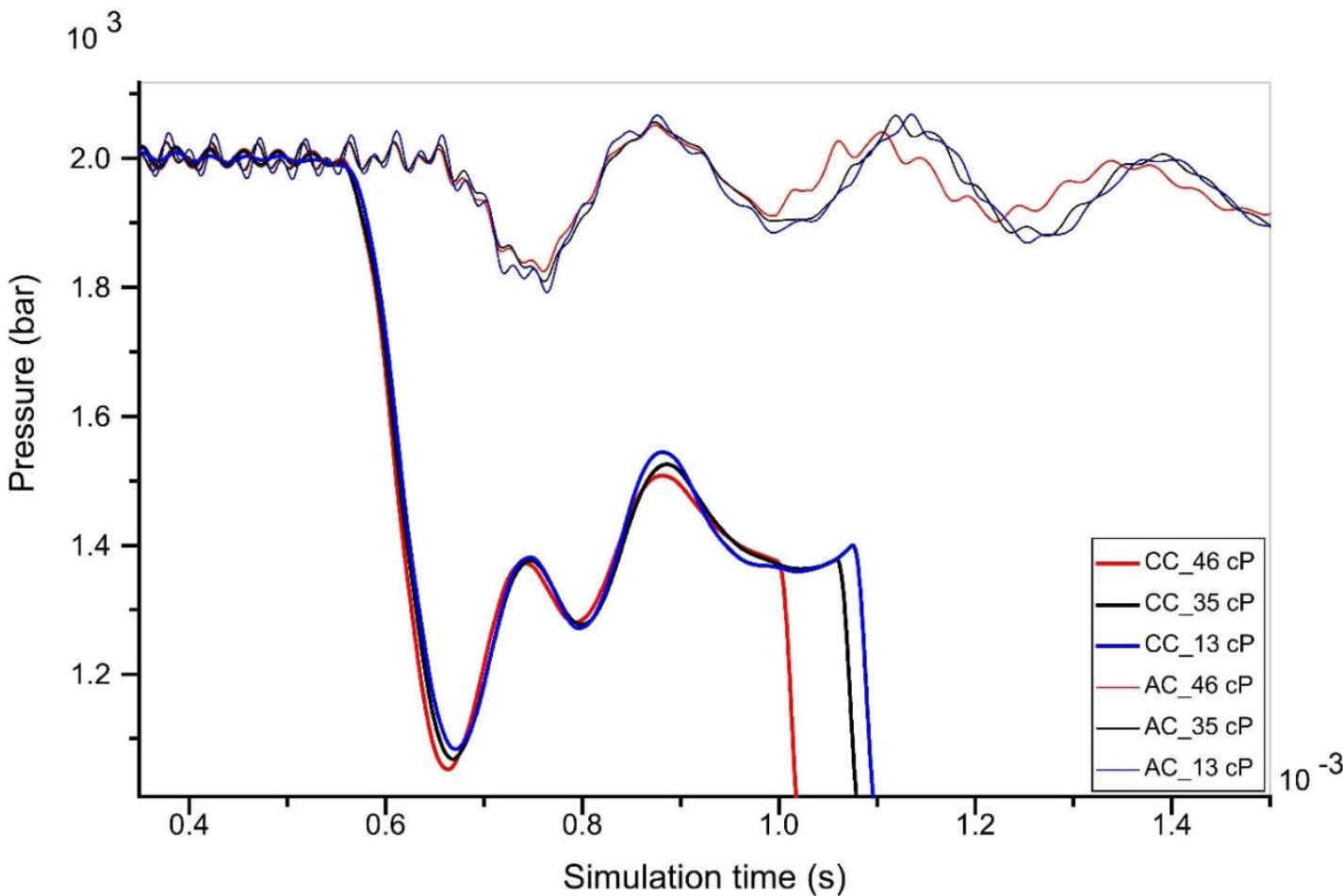

Fig. 20 Details of Section E in Fig. 19 


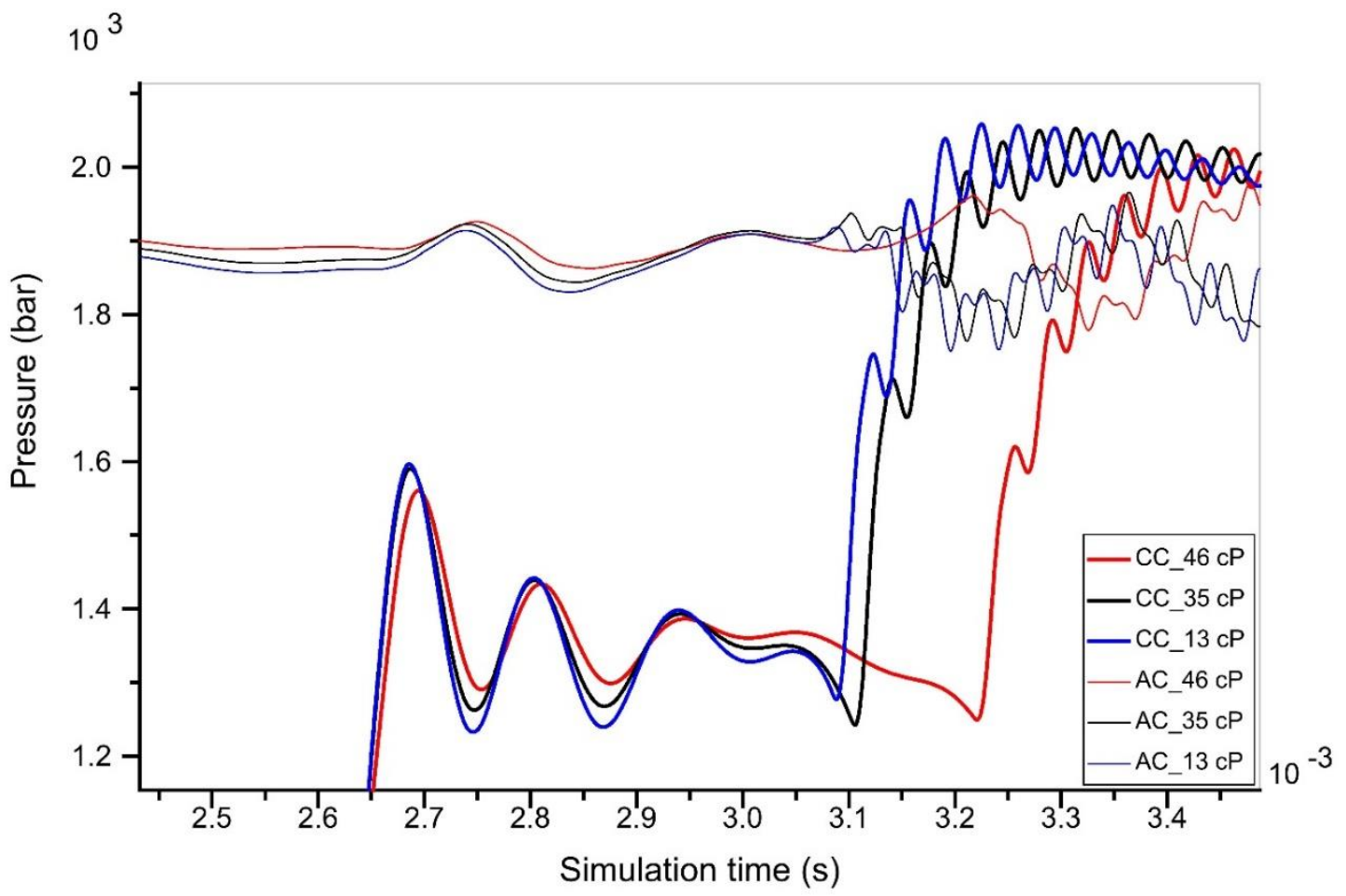

338 Fig. 21 Details of Section F in Fig. 19

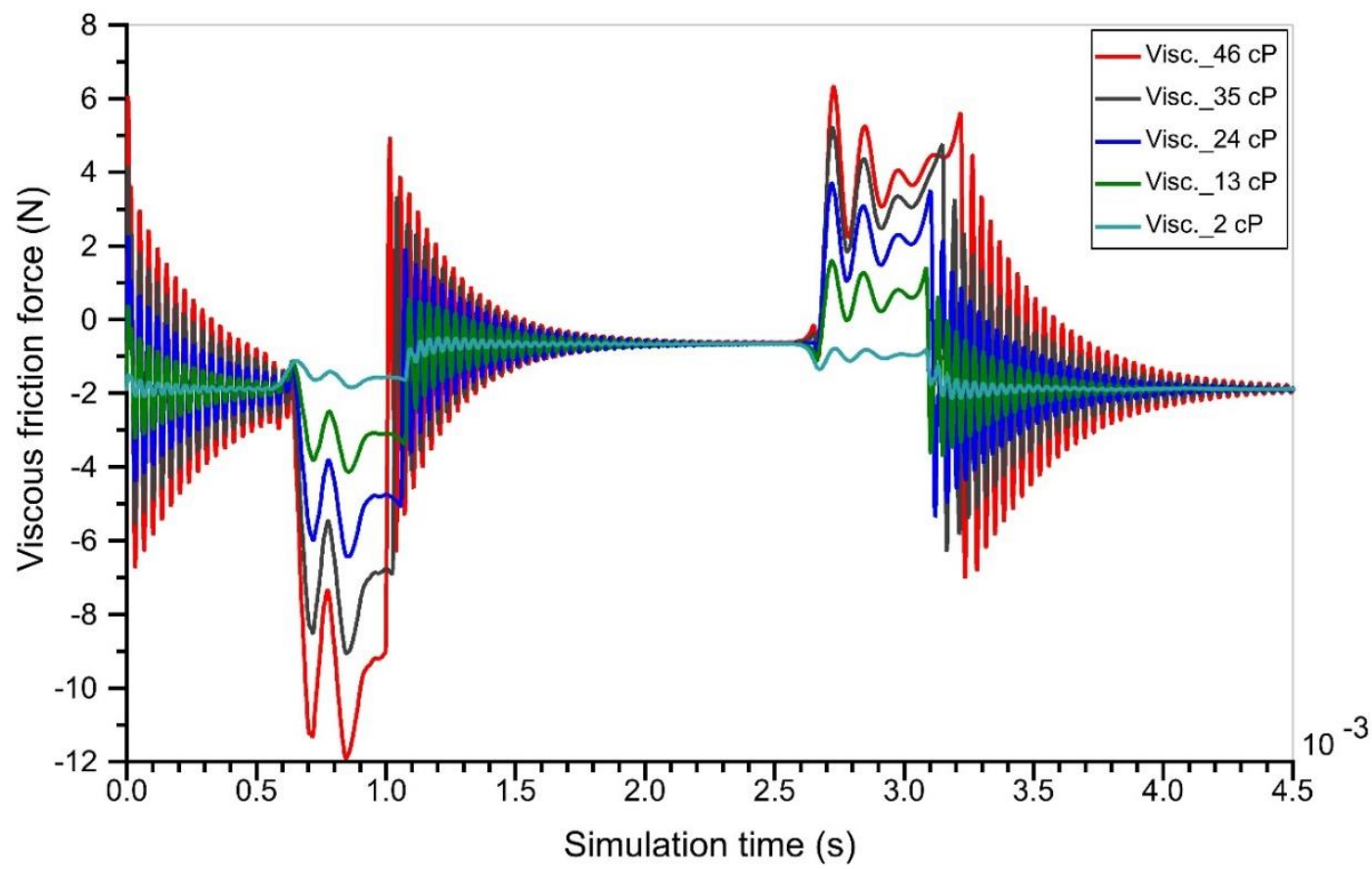

Fig. 22 Friction forces under different absolute viscosities 


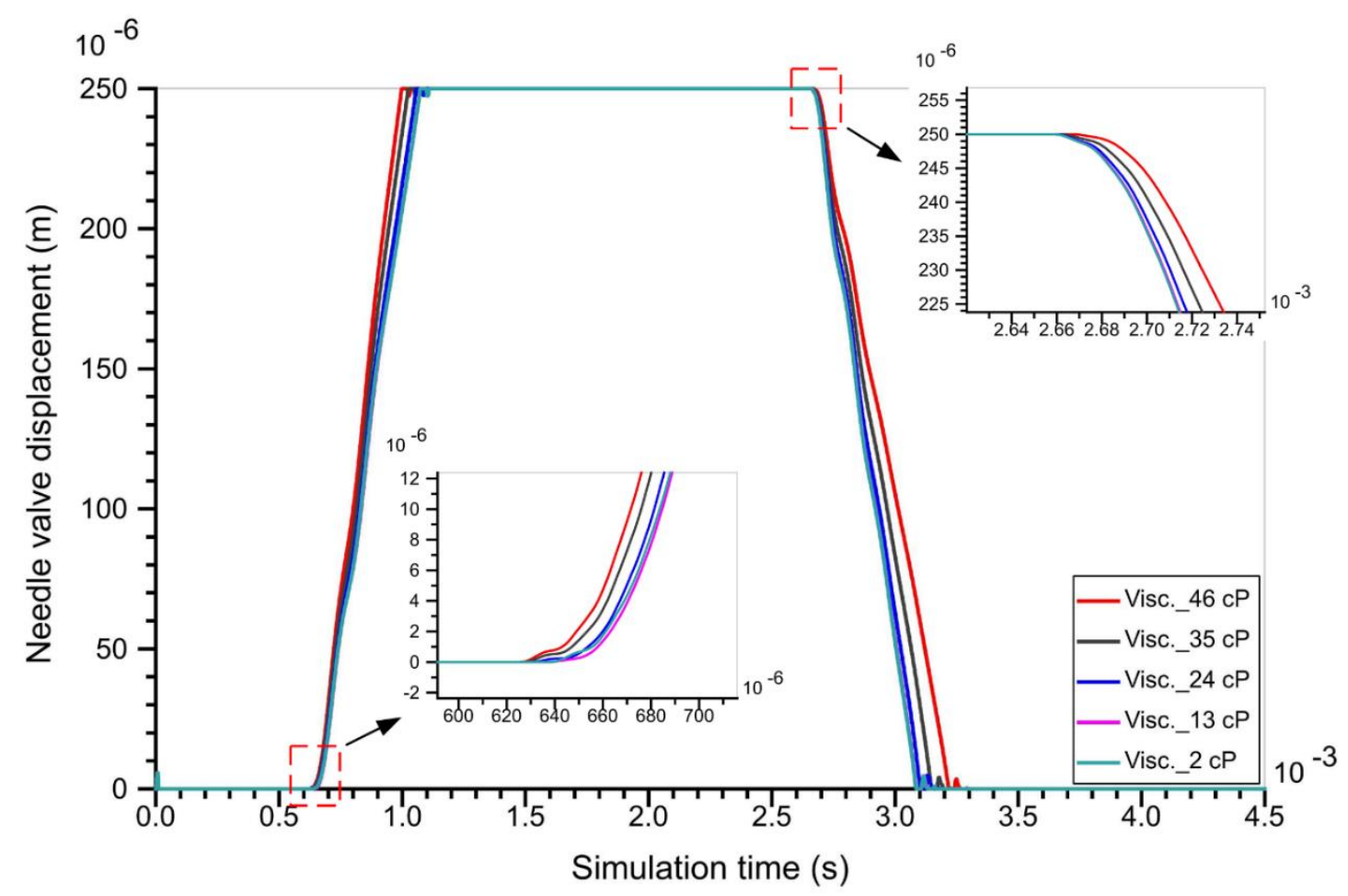

342 Fig. 23 Needle valve displacements under different absolute viscosity conditions

\section{5. Conclusions}

344 The effects of fuel properties (bulk modulus, density and absolute viscosity) on the injector

345 valve opening/closing delay and valve opening/closing time were investigated individually. A

346 fuel injector model was built and validated by injection rate and injection mass at three different

347 rail pressures. Then, a DOE model was built in modeFRONTIER software to study the effects

348 of the fuel properties on the injector dynamic response from a statistical point of view. The

349 effects of these properties were compared using an SS-ANOVA at both the low and high rail

350 pressures. And then reported by RSM function charts based on the DOE data. In addition, the details of the pressure differences and needle valve movements were also presented. The main conclusions are as follows: 
353 (1) The bulk modulus plays a dominant role in influencing the valve opening/closing delay at 354 the low rail pressure.

355 (2) At the high pressure, however, the effects of the absolute viscosity are dominant, while the 356 effects of the bulk modulus and the density are negligible.

357 (3) Both the valve opening delay and the valve closing delay decrease with an increase in the bulk modulus. A large valve opening time and a small valve closing time are the result of a 359 large bulk modulus.

360 (4) A high fuel density results in an increase in the valve opening/closing delay and the valve 361 opening/closing time, and vice versa.

362 (5) A high fuel viscosity results in a small valve opening delay and a large valve closing delay.

363 In addition, it generates a large pressure difference, which accelerates the needle movement to

364 achieve a short valve opening time, and slows down the needle valve movement when it is 365 returning to its seat, to get a large valve closing time.

\section{Acknowledgements}

367 The authors are grateful to the Department of Naval Architecture, Ocean and Marine

368 Engineering of the University of Strathclyde for its calculation support during the project.

369 Funding: This work was supported by the project 'Engineering Development of a Medium-

370 Speed Dual Fuel Engine (Ministry of Industry and Information Technology NO. (2013) 412, 
371 2)' from China and the project 'An Investigation into the Characteristics of High-pressure

372 Common Rail Injection System' from Lloyds Register of Shipping in the UK.

\section{References}

[1] Benajes J, Pastor JV, Payri R, Plazas AH. Analysis of the influence of diesel nozzle geometry in the injection rate characteristics. J Fluids Eng. 2004; 126: 63-71.

[2] Han JS, Lu PH, Xie XB, Lai MC, Henein NA. Investigation of diesel spray primary breakup and development for different nozzle geometries. SAE Paper 2002; 2002-01-2775.

[3] Payri R, Garcia JM, Salvador FJ, Gimeno J. Using spray momentum flux measurements to understand the influence of diesel nozzle geometry on spray characteristics. Fuel 2005; 84: $551-561$.

[4] Lahane S, Subramanian KA. Impact of nozzle holes configuration on fuel spray, wall impingement and NOx emission of a diesel engine for biodiesel-diesel blend (B20). Applied Thermal Engineering 2014; 64: 307-314.

[5] Salvador FJ, Martínez-López J, Caballer M, De Alfonso C. Study of the influence of the needle lift on the internal flow and cavitation phenomenon in diesel injector nozzles by CFD using RANS methods. Energy Conversion and Management 2013; 66: 246-256. 
[6] Moon S, Gao Y, Park S, Wang J, Kurimoto N, Nishijima Y. Effect of the number and position of nozzle holes on in- and near-nozzle dynamic characteristics of diesel injection. Fuel 2015; 150: 112-122.

[7] He Z, Zhong W, Wang Q, Jiang Z, Fu Y. An investigation of transient nature of the cavitating flow in injector nozzles. Applied Thermal Engineering 2013; 54: 56-64.

[8] Payri F, Payri R, Salvador FJ, Martínez-López J. A contribution to the understanding of cavitation effects in Diesel injector nozzles through a combined experimental and computational investigation. Computers \& Fluids 2012; 58: 88-101.

[9] Qiu T, Song X, Lei Y, Liu X, An X, Lai M. Influence of inlet pressure on cavitation flow in diesel nozzle. Applied Thermal Engineering 2016; 109: 364-372.

[10] He Z, Zhong W, Wang Q, Jiang Z, Fu Y. An investigation of transient nature of the cavitating flow in injector Nozzles. Applied Thermal Engineering 2013; 54: 46-64.

[11] Molina S, Salvador FJ, Carreres M, Jaramillo. A computational investigation on the influence of the use of elliptical orifices on the inner nozzle flow and cavitation development in diesel injector nozzles. Energy Conversion and Management 2014; 79: 114-127.

[12] Payri R, Salvador SJ. Gimeno J, Zapata LD. Diesel nozzle geometry influence on spray liquid-phase fuel penetration in evaporative conditions. Fuel 2008; 87: 1165-1176.

[13] Payri R, Salvador SJ. Gimeno J, Morena J. Effects of nozzle geometry on direct injection diesel engine combustion process. Applied Thermal Engineering 2009; 29: 2051-2060. 
[14] Wang B, Badawy T, Jiang Y, Xu H, Ghafourian A, Zhang X. Investigation of deposit effect on multi-hole injector spray characteristics and air/fuel mixing process. Fuel 2017; 191 : $10-24$.

[15] Payri R, Gimeno J, Bardi M, Plazas AH. Study liquid length penetration results obtained with a direct acting piezo electric injector. Applied Energy 2013; 106: 152-162.

[16] Payri R, Gimeno J, Viera JP, Plazas AH. Needle lift profile influence on the vapor phase penetration for a prototype diesel direct acting piezoelectric injector. Fuel 2013; 113: 257-265.

[17] Payri R, García-Oliver JM, Xuan T, Bardi M. A study on diesel spray tip penetration and radial expansion under reacting conditions. Applied Thermal Engineering 2015; 90: 619-629.

[18] Payri R, Viera JP, Pei YJ, Som S. Experimental and numerical study of lift-off length and ignition delay of a two-component diesel surrogate. Fuel 2015; 158: 957-967.

[19] Payri R, Salvador FJ, Manin J, Viera A. Diesel ignition delay and lift-off length through different methodologies using a multi-hole injector. Applied Energy 2016; 162: 541-550.

[20] Crookes RJ, Bob-Manuel KDH. RME or DME: A preferred alternative fuel option for future diesel engine operation. Energy Conversion and Management 2007, 48(11): 2971-2977.

[21] Cheng Q, Xu M, Zhang Z, Xie N. Investigation on the spray characteristics of standard gasoline, n-pentane, iso-octane and ethnaol with a novel heated tip SIDI injector. Applied Thermal Engineering 2017, 110: 539-552. 
[22] Dernotte J, Hespel C, Houillé S, Foucher F, Rousselle CM. Influence of fuel properties on the diesel injection process in nonvaporizing conditions. Atomization Sprays 2012; 22(6): 461492.

[23] Payri R, Salvador FJ, Gimeno J, Bracho G. Effect of fuel properties on diesel spray development in extreme cold conditions. Proc Inst Mech Eng, Part D: J Automobile Eng 2008; 222: 1743-1753.

[ 24 ] Salvador FJ, De la Morena J, Martínez-López J, Jaramillo D. Assessment of compressibility effects on internal nozzle flow in diesel injectors at very high injection pressures. Energy Conversion and Management 2017, 132: 221-230.

[25] Desantes JM, Salvador FJ, Carreres M, Jaramillo D. Experimental characterization of the thermodynamic properties of diesel fuels over a wide range of pressures and temperatures. SAE Int J Fuels Lubricants 2015; 8(1): 190-199.

[26] Salvador FJ, Gimeno J, De la Morena J, Carreres M. Using one-dimensional modeling to analyze the influence of the use of biodiesels on the dynamic behavior of solenoid-operated injectors in common rail systems: Results of the simulations and discussion. Energy Conversion and Management 2012; 54: 122-132.

[27 ] Han D, Duan Y, Wang C, Lin H, Huang Z. Experimental study on injection characteristics of fatty acid esters on a diesel engine common rail system. Fuel 2014; 123: 19-25.

[28] Salvador FJ, Gimeno J, Carreres M, Crialesi-Esposito M. Fuel temperature influence on the performance of a last generation common-rail diesel ballistic injector. Part I: Experimental 
mass flow rate measurements and discussion. Energy Conversion and Management 2016; 114 : 364-375.

[29] Payri R, Salvador FJ, Carreres M, De la Morena J. Fuel temperature influence on the performance of a last generation common-rail diesel ballistic injector. Part II: 1D model development, validation and analysis. Energy Conversion and Management 2016; 114: 376391.

[30] Boudy F, Seers P. Impact of physical properties of biodiesel on the injection process in a common-rail direct injection system. Energy Conversion and Management 2009; 50: 29052912.

[31] Han D, Li K, Duan Y, Lin H, Huang Z. Numerical study on fuel physical effects on the split injection processeson a common rail injection system. Energy Conversion and Management 2017; 134: 47-58.

[32] Payri R, Salvador FJ, Carreres M, DelaMorena J. Fuel temperature influence on the performance of a last generation common-rail diesel ballistic injector. Part II: 1D model development, validation and analysis. Energy Conversion and Management 2016; 114: 376391.

[33] Ando R, Koizumi M, Ishikawa T. Development of a simulation method for dynamic characteristics of fuel injector. IEEE TRANSACTIONS ON MAGNETICS 2001; 37 (5): 3715:3718. 
[34] Seykens XLJ, Somers LMT, Baert RSG. Detailed modelling of common rail fuel injection process. J Middle Eur Construct Des Cars (MECCA) 2005; 3: 30-39.

[35] Rahim R, Mamat R, Taib MY, Abdullah AA. Influence of fuel temperature on diesel engine performance operating with biodiesel blend. J Mech Eng Sci. 2012; 2: 226-236.

[36] Bianchi GM, Falfari S, Pelloni P, Kong SC, Reitz RD. Numerical analysis of high-pressure fast-response common rail injector dynamics. SAE TECHNICAL PAPER SERIES 2002; 2002-01-0213.

[37] Payri R, Salvador FJ, Martí-Aldaraví P, Martínez-López J. Using one-dimensional modelling to analyse the influence of the use of biodiesels on the dynamic behaviour of solenoid-operated injectors in common rail systems: Detailed injection system model. Energy Conversion and Management 2012, 54: 90-99.

[38] Salvador FJ, Plazas AH, Gimeno J, Carreres M. Complete modelling of a piezo actuator last-generation injector for diesel injection systems. International J of Engine Research 2014; 15 (1): 3-19.

[39] Taghavifar H, Jafarmadar S, Taghavifar H, Navid A. Application of DoE evaluation to introduce the optimum injection strategy-chamber geometry of diesel engine using surrogate epsilon-SVR. Applied Thermal Engineering 2016, 106: 56-66.

[40] Cioppa TM, Lucas TW. Efficient Nearly Orthogonal and Space-Filling Latin Hypercubes. Technometrics 2007; 49(1): 45-55. 
[41] Box GEP and Wilson KB. On the experimental attainment of optimum conditions (with discussion). Journal of the Royal Statistical Society Series B 1951; 13(1): 1-45.

[42] Rigoni E, Ricco L. Smoothing spline ANOVA for variable screening. ESTECO Technical Report 2011-007.

[43] Ali OM, Mamat R, Najafi G, Yusaf T, Ardebili SMS. Optimization of biodiesel-diesel blended fuel properties and engine performance with ether additive using statistical analysis and response surface methods. Energies 2015; 8(12): 14136-14150.

[44] Macián V, Bermúdez V, Payri R, Gimeno J. New technique for determination of internal geometry of a diesel nozzle with the use of silicone methodology. Exp Tech 2003; 27: 39-43.

[45] Hu N, Yang JG, Zhou PL, Hu Y. Study of the impact of structural parameters on the dynamic response of an electronic fuel injector. Energy Conversion and Management 2017; 136: 202-219.

[46] Binder RC. Fluid mechanics. Englewood Cliffs, New Jersey, USA: Prentice Hall; 1973. 